\title{
An Embedded Linear Model Three-Dimensional Fuzzy PID Control System for a Bionic AUV under Wave Disturbance
}

\author{
Da Lyu ${ }^{D},{ }^{1}$ Haoqin Su, ${ }^{1,2}$ Yun Li, ${ }^{1}$ Zijun Zhang, ${ }^{1}$ Hao Long, ${ }^{3,4}$ and Junbo Zhao ${ }^{1}$ \\ ${ }^{1}$ China Academy of Aerospace Aerodynamics, Beijing 100074, China \\ ${ }^{2}$ Caihong UAV Technology Co., Ltd, Beijing 100074, China \\ ${ }^{3}$ Beijing Key Laboratory of Information Service Engineering, Beijing Union University, Beijing 100101, China \\ ${ }^{4}$ College of Robotics, Beijing Union University, Beijing 100027, China \\ Correspondence should be addressed to Da Lyu; 2442070076@qq.com
}

Received 3 November 2021; Revised 28 January 2022; Accepted 11 February 2022; Published 4 March 2022

Academic Editor: Luis J. Yebra

Copyright $\odot 2022 \mathrm{Da}$ Lyu et al. This is an open access article distributed under the Creative Commons Attribution License, which permits unrestricted use, distribution, and reproduction in any medium, provided the original work is properly cited.

\begin{abstract}
This study provides a new embedded linear model (ELM) three-dimensional fuzzy PID control method for a bionic autonomous underwater vehicle (AUV), which is disturbed by ocean waves. The uncertainty of the ocean waves will make it difficult for the AUV to achieve good sailing quality, especially near the sea surface. In view of this problem, an ELM fuzzy PID controller, which adopts three-dimensional fuzzy control rules, is designed. In the ELM fuzzy PID controller, a linear model of AUV is established in order to actively perceive the effect of waves on AUV. Hence, the wave disturbance can be reflected in the control signal earlier and faster. Finally, three simulations are carried out to verify the control effect of the ELM fuzzy PID controller. An ocean wave disturbance model is established in order to simulate the force and the moment acting on the AUV. The results imply that compared with the classical PID controller and normal fuzzy PID controller, the ELM fuzzy PID controller can significantly enhance the stability of AUV and make the response faster and overshoot smaller.
\end{abstract}

\section{Introduction}

Wave disturbance to the AUV sailing near the sea surface has always been a problem that restricts its working capacity. The French developed the world's first AUV, Epaulard, in the 1970s [1]. After more than 40 years of development, AUV has been widely used in marine environment exploration [2, 3], marine mineral exploration [4], marine data collection [5], maritime alert [6], and other aspects.

One of the essential parts of AUV is the control system. The control system of AUV is equivalent to the brain of humans. The AUV system is a six-degree-of-freedom, nonlinear, strongly coupled, and model uncertain system [7]. It needs to face underwater wave disturbance and complex topography during its missions. Therefore, how to efficiently and stably control the AUV has become one of the most challenging problems. The research on the control system of an AUV is the key to solve this problem. How to improve the AUV control system under the disturbance of waves is the main issue of this study.
At present, classical and modern control theory has been widely used in industrial production [8], scientific experiments [9], aerospace [10], and military fields [11]. Taking PID control as an example, Wan [12] proposed a fractionalorder PID strategy, which has been successfully applied to the heading control, diving control, and path-following system of AUV on sea trial. By comparing simulations and experiments, satisfactory performance, such as overshoot, settling time, and steady-state error, has been achieved. Khodayari and Balochian [13] design a variable integral PID controller based on a disturbance observer (DO) for AUV with a torpedo exterior, and simulation shows that the proposed controller has better tracking and robustness in the presence of interference. Guerrero et al. [14] design a nonlinear PID controller based on a set of saturation functions for trajectory tracking on an underwater vehicle. The effectiveness and robustness of the controller are demonstrated through experiments. But for these control theories, they have a common premise, that is, an accurate 
mathematical model of the controlled object needs to be established [15-17]. However, the systems studied in various fields are becoming more and more complex. For those complex systems that are difficult to establish accurate models $[18,19]$, it is often inappropriate to use classical control theory or modern control theory. But using fuzzy control theory can often achieve the purpose of precise control [20].

Fuzzy logic control is abbreviated as fuzzy control. This theory was proposed by Professor Zadeh in the 1970s [21]. The most important part of a fuzzy controller is the fuzzy control law [22-24]. The fuzzy control law is the control experience summarized by researchers through the operation, learning, and accumulation of the controlled object system. These control experiences include the characteristics of the controlled object, the corresponding control strategies, and the performance indicators in various situations. The fuzziness of the controller is that the description of the fuzzy control law, which is usually natural language. The key of fuzzy control is to transform natural language into algorithm language for control. Rabah et al. [25] developed a fuzzy PI controller to adjust the parameters of the PI controller using the position and change in position data as input. The obtained results indicate that the proposed controller works well for tracking a moving target under different scenarios, especially during the night. In addition, Nouri et al. [26] propose a self-tuning fuzzy (STF) controller for the three-level boost converter. For each operating point, a proportional integral (PI) controller is designed. The results verify that the proposed control strategy can yield good performance. Farajdadian and Hosseini [27] designed fuzzy logic controllers (FLCs) for maximum power point tracking (MPPT) in a photovoltaic system, and then, fuzzy membership functions are optimized using the firefly algorithm (FA) to generate the proper duty cycle. The simulation results show that asymmetric fuzzy membership functions based on FA increase the tracking speed of MPPT and improve tracking accuracy. Septyan and Agustinah [28] propose the development of a fuzzy controller and a nonlinear dynamic feedback for an automated guided vehicle (AGV) with nonholonomic constraints. The fuzzy controller is designed using parallel distributed compensation with a 3state kinematic error model. Simulation results show that the AGV can track sudden big orientation change from the nonsmooth reference trajectory and initial position error. Raj and Mohan [29] propose four new models of TakagiSugeno (TS) type fuzzy controllers. The gain variations of the controller and the stability analysis of the closed-loop control system are investigated. Yan et al. [30] reported a high-order disturbance observer (HODO)-based adaptive fuzzy tracking controller for nonlinear systems with saturation nonlinearity, uncertainties, and external disturbances. A numerical simulation of a two-stage chemical reactor shows the effectiveness of the developed control strategy. Sun et al. [31] investigated the problem of adaptive fuzzy control for a class of nontriangular structural stochastic switched nonlinear systems with full-state constraints and designed an adaptive fuzzy stochastic switched control scheme based on the Barrier Lyapunov function. The effectiveness of the proposed control scheme is verified via simulation studies. Yang et al. [32] developed an adaptive fuzzy control scheme for a dual-arm robot, applied an approximate Jacobian matrix to address the uncertain kinematic control, and constructed a decentralized fuzzy logic controller to compensate for uncertain dynamics of the robotic arms and the manipulated object. The effectiveness of the proposed approach was illustrated by extensive simulation studies using a dual-arm robot. Chao et al. [33] reported an optimal fuzzy PID controller design based on conventional PID control and nonlinear factors. In this way, a fuzzy PID controller can be developed with less parameters and optimized by using the genetic algorithm (GA). The feasibility of this technique was demonstrated by simulation. Khodayari and Balochian [13] designed a new self-tuning fuzzy fractional-order PID (AFFOPID) controller based on a nonlinear MIMO structure for an AUV. Simulation results demonstrate that the proposed controller has good performance and significant robust stability in comparison to traditional tuned PID controllers.

This study proposes an ELM (embedded linear model) fuzzy PID controller, which adopts three-dimensional fuzzy control rules. Its structure is different from the self-tuning fuzzy fractional-order PID controller published before [13]. A simplified linear model is embedded in the controller in this study, and the fuzzy rules are three dimensional, which can more accurately adjust parameters online. The simulation test is designed to verify the effect of the control system under the disturbance of waves. Compared with the publicly reported control method of the AUV system, this control method uses an embedded linear model to sense the external disturbance, combined with a reasonable fuzzy rule design. Thus, the control method has a faster reaction speed and stronger control strength.

\section{Preliminary}

2.1. Introduction of the AUV Studied in This Study. The bionic AUV shown in Figure 1 adopts a dolphin-like appearance. The propulsion system consists of two propellers $T_{1}, T_{1}$ mounted on the horizontal tail. The pitching motion of the AUV is controlled by the angle of horizontal rudder $\delta_{e}$, and the heading motion is controlled by the different $T_{1}-T_{2}$ between the two propellers. In addition, this AUV is underactuated, as there are no actuators in the roll direction. But the hydrodynamic restoring force is designed to be large enough in the roll direction.

2.2. Mathematical Model of the AUV. In order to study the effect of the control method described in this study, the mathematical model of the AUV is needed for the following simulation. In this study, the earth-fixed coordinate and the body-fixed coordinate, which are shown in Figure 2 are selected to describe the motion of AUV. The origin of the earth-fixed coordinate with axis $\left[x_{e}, y_{e}, z_{e}\right]$ is selected on the ground, the $x_{e}$ axis points to the north direction in the horizontal plane, the $y_{e}$ axis is straight up, and the $z_{e}$ axis is perpendicular to the $x_{e}$ and $y_{e}$ axis, forming a right-handed system with them. The origin of the body-fixed coordinate with axis $\left[x_{b}, y_{b}, z_{b}\right]$ is selected at the center of buoyance of 


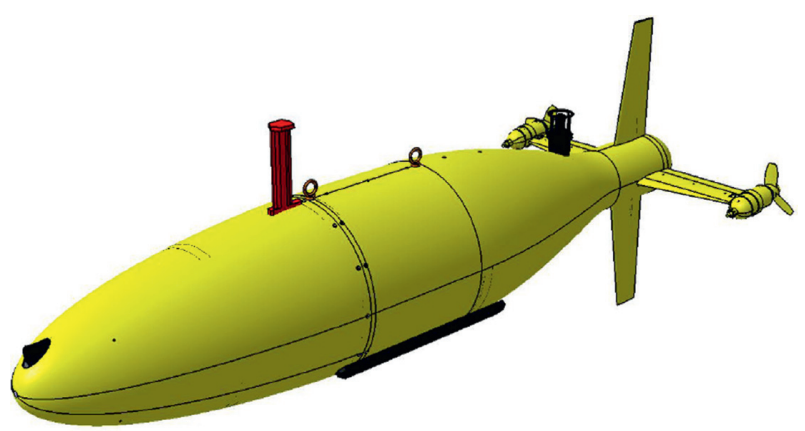

FIgURE 1: The bionic AUV diagram described in this study.

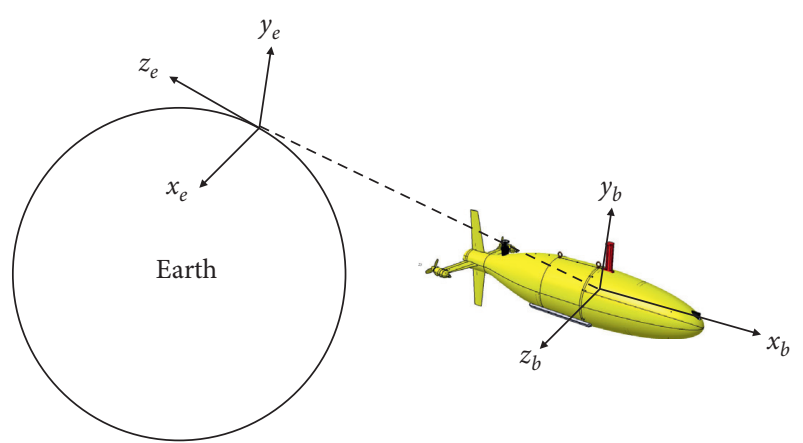

FIgURE 2: The earth-fixed coordinate and the body-fixed coordinate.

AUV. $x_{b}$ axis points forward along the longitudinal axis of AUV, $y_{b}$ axis points upward perpendicular to $X$ axis, and $z_{b}$ axis is perpendicular to $x_{b}$ axis and $y_{b}$ axis, forming a righthanded system with them.

In order to establish the mathematical model of the AUV, the following assumptions were made: the AUV is a rigid body; the AUV is completely immersed in the sea; and the influence of the curvature and rotation of the Earth are not considered.
According to the theorem of momentum, the kinetic equations of the AUV are established in the body coordinate system of the AUV as in equation (1). In the formula, $\mathbf{F}$ is the projection of the resultant force of all external forces received by the AUV on the body coordinate system, and $\mathbf{M}$ is the projection of the resultant moment of force received by the AUV on the body coordinate system. $\mathbf{Q}$ is the momentum of AUV. K is the moment of momentum of AUV.

$$
\left\{\begin{array}{l}
\frac{\mathrm{d} \mathbf{Q}}{\mathrm{d} t}+\boldsymbol{\omega} \times \mathbf{Q}=\mathbf{F}, \\
\frac{\mathrm{d} \mathbf{K}}{\mathrm{d} t}+\boldsymbol{\omega} \times \mathbf{K}+\mathbf{v}_{0} \times \mathbf{Q}=\mathbf{M} .
\end{array}\right.
$$

The momentum $\mathbf{Q}$ and the moment of momentum $\mathbf{K}$ are as in equation (2), in which, $m$ is the mass of AUV, $\mathbf{v}_{c}$ is the velocity vector of mass center relative to earth-fixed coordinate, $\mathbf{r}_{c}$ is the vector of mass center to buoyance center, $\mathbf{v}_{0}$ is the velocity vector of buoyance center, $\omega$ is the angular velocity of AUV, and $\mathbf{J}_{0}$ is the moment of inertia matrix of AUV relative to the buoyance center.

$$
\left\{\begin{array}{l}
\mathbf{Q}=m \mathbf{v}_{c}, \\
\mathbf{K}=\mathbf{J}_{0} \cdot \boldsymbol{\omega}+\mathbf{r}_{c} \times m \mathbf{v}_{0} .
\end{array}\right.
$$

In equation (1), the external forces on the AUV include ideal fluid inertial force, viscous position force, viscous damping force, buoyancy, gravity, propeller thrust, and propeller unbalanced moment. [34].

All the external forces and moments acting on the AUV are substituted into equation (1), and the higher-order small quantities of AUV motion parameters are ignored. Then, the kinetic equation of the AUV can be obtained as equations (3)-(6).

$$
\begin{aligned}
& \left\{\begin{array}{l}
\left(m+\lambda_{11}\right) \dot{v}_{x}+m z_{c} \dot{\omega}_{y}-m y_{c} \dot{\omega}_{z}+m\left[v_{z} \omega_{y}-v_{y} \omega_{z}+y_{c} \omega_{x} \omega_{y}+z_{c} \omega_{x} \omega_{z}-x_{c}\left(\omega_{y}^{2}+\omega_{z}^{2}\right)\right] \\
=T_{1}+T_{2}-0.5 \cdot C_{x S} \rho v^{2} S-\Delta G \sin \theta\left(m+\lambda_{22}\right) \dot{v}_{y}+\left(m x_{c}+\lambda_{26}\right) \dot{\omega}_{z}-m z_{c} \dot{\omega}_{x} \\
+m\left[v_{x} \omega_{z}-v_{z} \omega_{x}+z_{c} \omega_{y} \omega_{z}+x_{c} \omega_{x} \omega_{y}-y_{c}\left(\omega_{x}^{2}+\omega_{z}^{2}\right)\right]=0.5 \cdot\left(C_{y}^{\alpha} \alpha+C_{y}^{\delta_{e}} \delta_{e}+C_{y}^{\omega_{z}} \bar{\omega}_{z}\right) \\
\rho v^{2} S-\Delta G \cos \theta \cos \varphi\left(m+\lambda_{33}\right) \dot{v}_{z}-\left(m x_{c}-\lambda_{35}\right) \dot{\omega}_{y}+m y_{c} \dot{\omega}_{x} \\
+m\left[v_{y} \omega_{x}-v_{x} \omega_{y}+x_{c} \omega_{z} \omega_{x}+y_{c} \omega_{y} \omega_{z}-z_{c}\left(\omega_{x}^{2}+\omega_{y}^{2}\right)\right] \\
=0.5 \cdot\left[C_{z}^{\beta} \beta+C_{z}^{\Delta T}\left(T_{1}-T_{2}\right)+C_{z}^{\omega_{y}} \bar{\omega}_{y}\right] \rho v^{2} S+\Delta G \cos \theta \sin \varphi \\
+\left(J_{z z}-J_{y y}\right) \omega_{y} \omega_{z}=0.5 \cdot \rho v^{2} S L\left[m_{x}^{\beta} \beta+m_{x}^{\Delta T}\left(T_{1}-T_{2}\right)+m_{x}^{\bar{\omega}_{x}} \bar{\omega}_{x}+m_{x}^{\bar{\omega}_{y}} \bar{\omega}_{y}\right] \\
+G \cos \theta\left(y_{c} \sin \varphi+z_{c} \cos \varphi\right) \\
\left(J_{y y}+\lambda_{55}\right) \dot{\omega}_{y}+m z_{c} \dot{v}_{x}-\left(m x_{c}-\lambda_{35}\right) \dot{v}_{z}+m z_{c}\left(v_{z} \omega_{y}-v_{y} \omega_{z}\right)+m x_{c}\left(v_{x} \omega_{y}-v_{y} \omega_{x}\right) \\
+\left(J_{x x}-J_{z z}\right) \omega_{z} \omega_{x}=0.5 \cdot \rho v^{2} S L\left[m_{y}^{\beta} \beta+m_{y}^{\Delta T}\left(T_{1}-T_{2}\right)+m_{y}^{\omega_{x}} \bar{\omega}_{x}+m_{y} \bar{\omega}_{y}\right]-G\left(x_{c} \cos \theta \sin \varphi+z_{c} \sin \theta\right) \\
\left(J_{z z}+\lambda_{66}\right) \dot{\omega}_{z}-m y_{c} \dot{v}_{x}+\left(m x_{c}+\lambda_{26}\right) \dot{v}_{y}+m x_{c}\left(v_{x} \omega_{z}-v_{z} \omega_{x}\right)+m y_{c}\left(v_{y} \omega_{z}-v_{z} \omega_{y}\right)+\left(J_{y y}-J_{x x}\right) \omega_{x} \omega_{y} \\
=0.5 \cdot \rho v^{2} S L\left(m_{z}^{\alpha} \alpha+m_{z}^{\delta_{e}} \delta_{e}+m_{z}^{\bar{\omega}_{z}} \bar{\omega}_{z}\right)+G\left(y_{c} \sin \theta-x_{c} \cos \theta \cos \varphi\right)
\end{array}\right.
\end{aligned}
$$




$$
\begin{aligned}
& \left\{\begin{array}{l}
\dot{\theta}=\omega_{y} \sin \varphi+\omega_{z} \cos \varphi, \\
\dot{\psi}=\omega_{y} \sec \theta \cos \varphi-\omega_{z} \sec \theta \sin \varphi, \\
\dot{\varphi}=\omega_{x}-\omega_{y} \tan \theta \cos \varphi+\omega_{z} \tan \theta \sin \varphi,
\end{array}\right. \\
& \left\{\begin{array}{l}
\dot{x}_{0}=v_{x} \cos \theta \cos \psi+v_{y}(\sin \psi \sin \varphi-\sin \theta \cos \psi \cos \varphi)+v_{z}(\sin \psi \cos \varphi+\sin \theta \cos \psi \sin \varphi), \\
\dot{y}_{0}=v_{x} \sin \theta+v_{y} \cos \theta \cos \varphi-v_{z} \cos \theta \sin \varphi, \\
\dot{z}_{0}=-v_{x} \cos \theta \sin \psi+v_{y}(\cos \psi \sin \varphi-\sin \theta \sin \psi \cos \varphi)+v_{z}(\cos \psi \cos \varphi-\sin \theta \sin \psi \sin \varphi)
\end{array}\right.
\end{aligned}
$$

Among them, equation (3) is the force equation in the directions of the three-body coordinate axis, and equation (4) is the moment equation in the directions of the threebody coordinate axis. Equations (5) and (6) are the coordinate transformation equations of angular velocity and velocity between two coordinate systems, respectively. In the equations, $\alpha$ is the attack angle (head up is positive). $\beta$ is the sideslip angle (right deviation is positive). $\delta_{e}$ is the horizontal rudder angle (upward deflection is positive). $V$ is the volume of AUV. $\theta$ is the pitch angle of AUV (along the positive direction of $z_{b}$ axis, clockwise is positive). $\varphi$ is the roll angle of AUV (along the positive direction of $x_{b}$ axis, clockwise is positive). $\psi$ is the yaw angle of AUV (along the positive direction of $y_{b}$ axis, clockwise is positive). $T_{1}$ is the thrust of the propellor $1 . T_{2}$ is the thrust of the propellor 2. $\lambda_{i j}$ is the added mass of the AUV. $\Delta G$ is the resultant force of gravity and buoyancy. The other mainly used parameters in the equation are shown in Table 1.

\section{Design Scheme of ELM Fuzzy PID Controller}

3.1. The Embedded Model and the Fuzzy Logic. In this study, we embedded a simplified linear model of the AUV into the controller. In order to obtain an accurate linear model, the mathematical model of the AUV established above has been simplified and divided into the vertical motion model (7) and the horizontal motion model (9) according to the small disturbance theory [35].

In order to ensure the stability of the control system, the accuracy of the embedded linear model needs to be verified. Figure 3 shows the comparison between the simulation results of the embedded linear model and the results of the real AUV lake test data with a 6-degree yaw rudder in the lateral direction. Figure 4 shows the comparison between the simulation results of the embedded linear model and the real AUV lake test data with a 6-degree elevator in the pitch direction. It can be seen from the results that the error of the embedded linear model and the real experimental data is small in the yaw and pitch directions. The error of the yaw direction and pitch direction is both less than $5 \%$, so it can be used to reflect the motion of the actual AUV without disturbance.

$$
\begin{aligned}
& {\left[\begin{array}{c}
\dot{\alpha} \\
\dot{\omega}_{z} \\
\dot{\theta} \\
\dot{d}
\end{array}\right]=\left[\begin{array}{cccc}
\frac{a_{21} a_{34}-a_{31} a_{24}}{a_{23} a_{31}-a_{21} a_{33}} \frac{a_{21} a_{32}-a_{31} a_{22}}{a_{23} a_{31}-a_{21} a_{33}} & 0 & 0 \\
\frac{a_{33} a_{24}-a_{23} a_{34}}{a_{23} a_{31}-a_{21} a_{33}} & \frac{a_{33} a_{22}-a_{23} a_{32}}{a_{23} a_{31}-a_{21} a_{33}} & 0 & 0 \\
0 & 1 & 0 & 0 \\
-v_{0} & 0 & v_{0} & 0
\end{array}\right] \text {, }} \\
& {\left[\begin{array}{c}
\alpha \\
\omega_{z} \\
\theta \\
d
\end{array}\right]+\left[\begin{array}{c}
\frac{a_{31} a_{25}-a_{21} a_{35}}{a_{23} a_{31}-a_{21} a_{33}} \\
\frac{a_{23} a_{35}-a_{33} a_{25}}{a_{23} a_{31}-a_{21} a_{33}} \\
0 \\
0
\end{array}\right] \cdot \delta_{e} .}
\end{aligned}
$$


TABLE 1: The mainly used parameters of the AUV in the equation.

\begin{tabular}{|c|c|c|c|}
\hline Variable names & Data value & Unit & Remarks \\
\hline$M$ & 100 & $\mathrm{Kg}$ & Mass \\
\hline$B$ & 981 & $N$ & Buoyancy \\
\hline$J_{x x}$ & 28.9 & $\mathrm{Kg} \cdot \mathrm{m}^{2}$ & Moment of inertia about $x$ axis \\
\hline$J_{y y}$ & 677 & $\mathrm{Kg} \cdot \mathrm{m}^{2}$ & Moment of inertia about $y$ axis \\
\hline$J_{z z}^{y y}$ & 677 & $\mathrm{Kg} \cdot \mathrm{m}^{2}$ & Moment of inertia about $z$ axis \\
\hline$L$ & 2.6 & $m$ & Length of the AUV \\
\hline$C_{x}$ & 0.14 & 1 & Coefficient of drag \\
\hline$L_{d}$ & 0.9 & $m$ & Distance of the two propeller \\
\hline$C_{z}^{\bar{\omega}_{y}}$ & 1.17 & 1 & Derivative of $C_{z}$ to $\bar{\omega}_{y}$ \\
\hline$C_{z}^{\alpha}$ & 2.32 & 1 & Derivative of $C_{z}$ to $\alpha$ \\
\hline$C_{z}^{\delta_{e}}$ & 0.51 & 1 & Derivative of $C_{z}$ to $\delta_{e}$ \\
\hline$M_{y}^{\alpha}$ & 0.69 & 1 & Derivative of $M_{y}$ to $\alpha$ \\
\hline$M_{y}^{\delta_{e}}$ & -0.28 & 1 & Derivative of $M_{y}$ to $\delta_{e}$ \\
\hline$C_{y}^{\beta}$ & -2.32 & 1 & Derivative of $C_{y}$ to $\beta$ \\
\hline$M_{z}^{\beta}$ & 0.69 & 1 & Derivative of $M_{z}$ to $\beta$ \\
\hline$x_{c}$ & 0.12 & $\mathrm{~m}$ & Distance between mass center and buoyancy center on $x_{b}$ axis \\
\hline$y_{c}$ & 0.03 & $\mathrm{~m}$ & Distance between mass center and buoyancy center on $y_{b}$ axis \\
\hline$z_{c}$ & 0 & $\mathrm{~m}$ & Distance between mass center and buoyancy center on $z_{b}$ axis \\
\hline
\end{tabular}

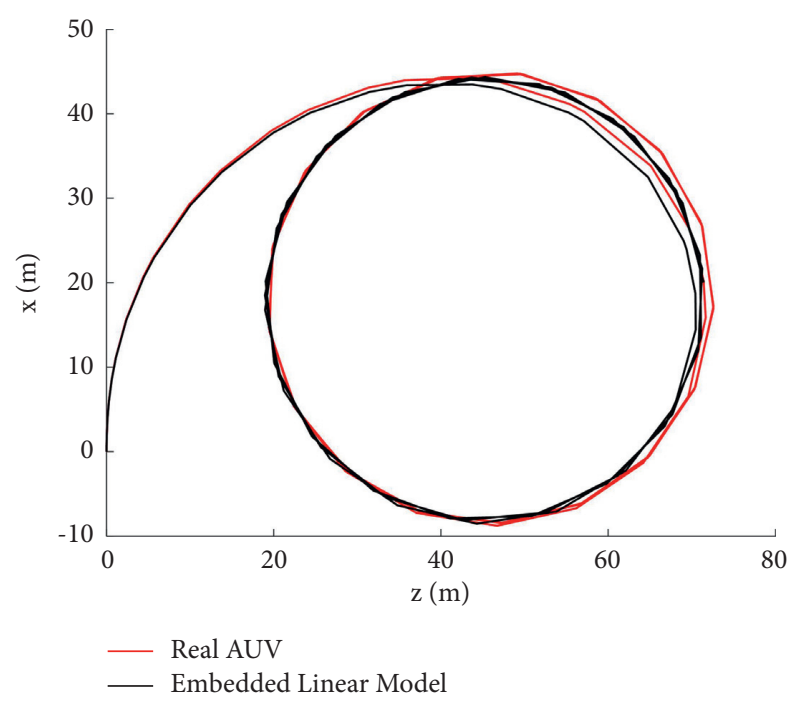

FIGURE 3: Simulation results of the embedded linear model and the results of the real AUV lake test data with a 6-degree yaw rudder.

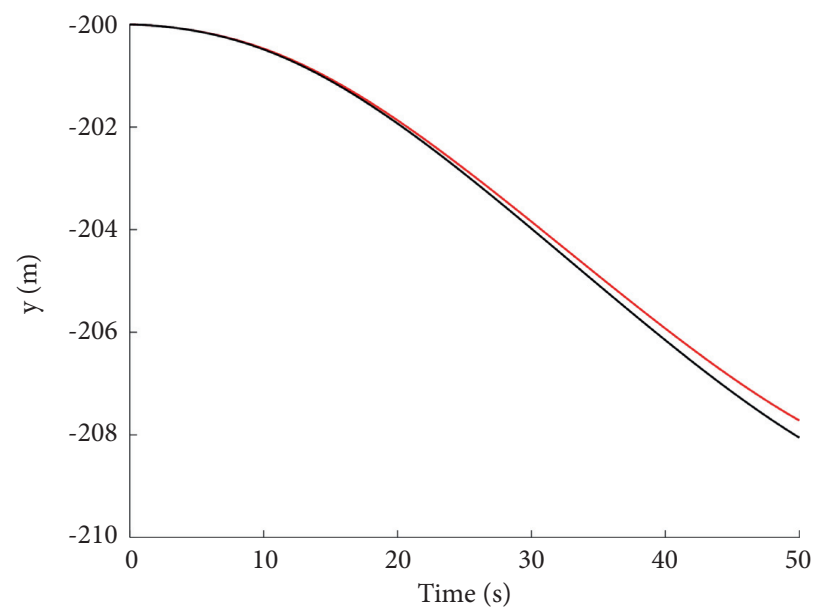

Real AUV
Embedded Linear Model

FIgURE 4: Simulation results of the embedded linear model and the real AUV lake test data with a 6-degree elevator. 
$d$ is the depth of the AUV. The coefficients in equation (7) are defined as follows:

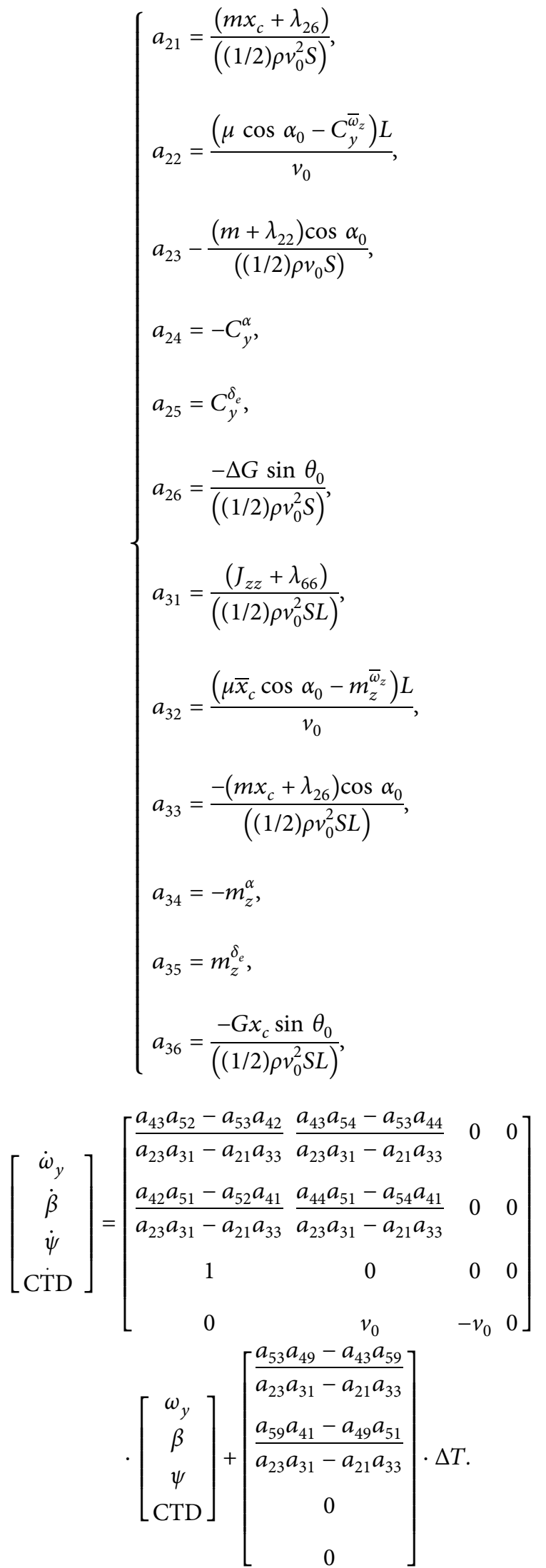

CTD is the cross-track distance of the AUV. The coefficients in equation (9) are defined as follows:

$$
\left\{\begin{aligned}
& a_{41}= \frac{\left(\lambda_{35}-m x_{c}\right)}{\left((1 / 2) \rho v_{0}^{2} S\right)} \\
& a_{42}= \frac{-\left(\mu+C_{z}^{\bar{\omega}_{y}}\right) L}{v_{0}} \\
& a_{43}= \frac{\left(m+\lambda_{33}\right)}{\left((1 / 2) \rho v_{0} S\right)} \\
& a_{44}=-C_{z}^{\beta}, \\
& a_{49}= C_{z}^{\delta_{r}}, \\
& a_{54}=-m_{y}^{\beta} . \\
& a_{59}= m_{y}^{\delta_{r}}, \\
& a_{51}= \frac{\left(m_{y y}+\lambda_{55}\right)}{\left((1 / 2) \rho v_{0}^{2} S L\right)} \\
&\left.a_{y 3}-\mu \bar{x}_{c}\right) L\left((1 / 2) \rho v_{0} S L\right) \\
& v_{0}
\end{aligned}\right.
$$

In this study, the basic design idea of the ELM fuzzy PID controller is shown in Figure 5. The feedback state error between the linear model and the actual AUV is obtained, and then, it is inputted into the controller together with the error of the control quantity and the error derivative of the control quantity.

It is assumed that the feedback state vector of the linear model is as follows:

$$
\widetilde{\mathbf{X}}=\left[\begin{array}{llllllll}
\widetilde{\alpha} & \widetilde{\omega}_{z} & \widetilde{\theta} & \widetilde{d} & \widetilde{\beta} & \widetilde{\omega}_{y} & \widetilde{\psi} & \widetilde{\mathrm{CTD}}
\end{array}\right]^{T}=\left[\begin{array}{lll}
\mathbf{L}\left(\delta_{e}\right) & \mathbf{Y}(\Delta T)
\end{array}\right]^{T},
$$

where the function $\mathbf{L}\left(\delta_{e}\right)$ is the solution of equation (7) when the horizontal rudder angle is $\delta_{e}$. The $\mathrm{Y}(\Delta T)$ is the solution of equation (9) when the propeller differential quantity is $\Delta T . \mathbf{L}\left(\delta_{e}\right)$ and $\mathbf{Y}(\Delta T)$ can be derived from the solution of nonhomogeneous state equation of linear time-invariant system as follows: 


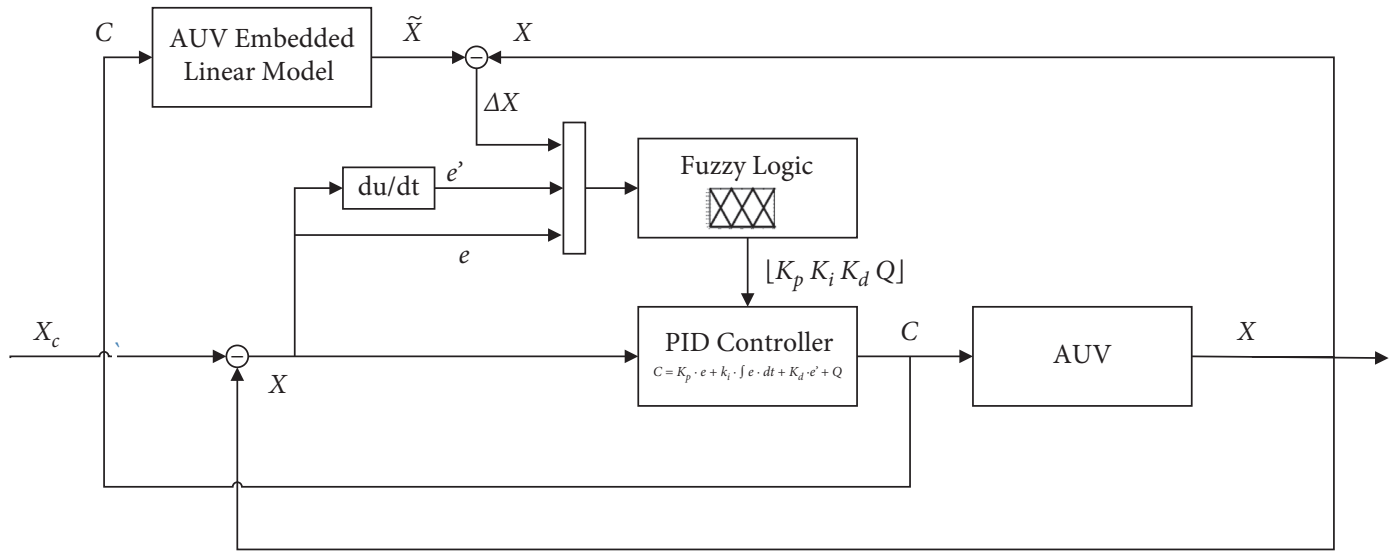

FIGURe 5: Design of the embedded linear model (ELM) fuzzy PID control method.

$$
\left[\begin{array}{c}
\mathbf{L}\left(\delta_{e}\right) \\
\mathbf{Y}(\Delta T)
\end{array}\right]=\left[\begin{array}{c}
e^{\mathbf{A}_{1}\left(t-t_{0}\right)} x_{1}\left(t_{0}\right)+\int_{t_{0}}^{t} e^{\mathbf{A}_{1}(t-\tau)} \mathbf{B}_{1} \delta_{e}(\tau) \mathrm{d} \tau \\
e^{\mathbf{A}_{2}\left(t-t_{0}\right)} x_{2}\left(t_{0}\right)+\int_{t_{0}}^{t} e^{\mathbf{A}_{2}(t-\tau)} \mathbf{B}_{2} \Delta T(\tau) \mathrm{d} \tau
\end{array}\right]
$$

where $\mathbf{A}_{1}$ is the state matrix of AUV vertical motion system. $\mathbf{B}_{1}$ is the control matrix of AUV vertical motion system. $\mathbf{A}_{2}$ is the state matrix of AUV horizontal motion system. $\mathbf{B}_{2}$ is the control matrix of AUV horizontal motion system. The feedback state vector of the actual AUV is as follows:

$$
\mathbf{X}=\left[\alpha \omega_{z} \theta d \beta \omega_{y} \psi \mathrm{CTD}\right]^{T} .
$$

The expected state vector of the AUV is as follows:

$$
\mathbf{X}_{c}=\left[\begin{array}{llllllll}
\alpha_{c} & \omega_{z c} & \theta_{c} & d_{c} & \beta_{c} & \omega_{y c} & \psi_{c} & \mathrm{CTD}_{c}
\end{array}\right]^{T} .
$$

Hence, the feedback state error between the linear model and the actual AUV is as follows:

$$
\Delta X(i)=\tilde{X}(i)-X(i)
$$

The error between the expected and actual control quantity is as follows:

$$
e(i)=X_{c}(i)-X(i)
$$

The derivative of error between the expected and actual control quantity is as follows:

$$
e^{\prime}(i)=X_{c}^{\prime}(i)-X^{\prime}(i)
$$

The controller adopts three-dimensional fuzzy control rules, in which the input variables of the controller consist of the feedback state error $\Delta X$, the control quantity error $e$, and the derivative of control quantity error $e^{\prime}$. The output includes the three control parameters of the controller $K_{p}, K_{i}$, and $K_{d}$, and the control compensation $Q$. The four parameters are adaptively adjusted according to the changes in the external environment and working conditions. The control law can be expressed as follows:

$$
C=K_{p} \cdot e+K_{i} \cdot \int e \cdot \mathrm{d} t+K_{d} \cdot e^{\prime}+Q
$$

where

$$
\left[K_{p} K_{i} K_{d} Q\right]=F\left(e e^{\prime} \Delta X\right) \text {. }
$$

Relationship $F$ is fuzzy logic, which includes fuzzy rules and membership functions. In this study, the fuzzy controller adopted a three-input and four-output structure. The inputs included the feedback state error $\Delta X$ between the linear model and the actual AUV, the control quantity error $e$, and the derivative of the control quantity error $e^{\prime}$. The output includes the three PID control parameters $K_{p}, K_{i}$, and $K_{d}$, and the control compensation $Q$. The fuzzy control set of $\Delta X, e, e^{\prime}$, and $Q$ is $\{\mathrm{NL} N M Z \mathrm{PM} \mathrm{PL}\}$, respectively, representing negative large, negative middle, zero, positive middle, and positive large. The fuzzy control set of $K_{p}, K_{i}$, and $K_{d}$ is $\{Z S M L\}$, which means zero, small, medium, and large, respectively.

The fuzzy rules about the three control parameters $K_{p}$, $K_{i}$, and $K_{d}$ of PID controller can be design as the fuzzy rules by Chao et al. [33]. The fuzzy rules about $Q$ mainly depend on $\Delta X(i)$. As an example, for the depth control loop in vertical motion, $\Delta X(i)$ is $\widetilde{d}-d$. According to the engineering experience, there are the following relationships: if $\widetilde{d}-d$ is a large/small positive number, it proves that AUV is more disturbed by waves in positive direction. Then, the compensation $Q_{\text {depth }}$ should be negatively large/small. It is analyzed in a similar way, if $\widetilde{d}-d$ is a large/small negative number, and the compensation $Q_{\text {depth }}$ should be positively large/small. Then, the fuzzy rules are formulated in Table 2.

The membership function of the fuzzy control rules adopted the triangular membership function, as shown in Figure 6. The membership function is used to describe the membership degree of variables. The closer the membership function value is to 1 , the more certain the input variable belongs to the set. The closer the membership function is to 0 , the more uncertain the input variable belongs to the set. 
TABLe 2: Fuzzy control rule table of ELM fuzzy PID controller.

\begin{tabular}{|c|c|c|c|c|c|c|c|c|c|c|c|c|c|c|c|c|c|c|c|c|c|c|c|}
\hline & & & & \multicolumn{5}{|c|}{$\begin{array}{c}K_{p} \\
e^{\prime}\end{array}$} & \multicolumn{5}{|c|}{$\begin{array}{c}K_{i} \\
e^{\prime}\end{array}$} & \multicolumn{5}{|c|}{$\begin{array}{c}K_{d} \\
e^{\prime}\end{array}$} & \multicolumn{5}{|c|}{$\begin{array}{l}Q \\
e^{\prime}\end{array}$} \\
\hline & & & & NL & $\mathrm{NM}$ & Z & $\mathrm{PM}$ & PL & $\mathrm{NL}$ & $\mathrm{NM}$ & Z & $\mathrm{PM}$ & PL & $\mathrm{NL}$ & $\mathrm{NM}$ & Z & $\mathrm{PM}$ & PL & NL & NM & $\mathrm{Z}$ & $\mathrm{PM}$ & PL \\
\hline \multirow{25}{*}{$\Delta X$} & \multirow{5}{*}{$\mathrm{NL}$} & \multirow{5}{*}{$e$} & NL & $\mathrm{M}$ & $\mathrm{L}$ & $\mathrm{L}$ & $\mathrm{L}$ & $\mathrm{M}$ & $\mathrm{Z}$ & $\mathrm{Z}$ & $\mathrm{Z}$ & $\mathrm{Z}$ & Z & $S$ & $S$ & $\mathrm{Z}$ & $S$ & $S$ & PL & PL & $\mathrm{PM}$ & NL & NL \\
\hline & & & $\mathrm{NM}$ & $S$ & S & $\mathrm{M}$ & S & $S$ & $S$ & $\mathrm{M}$ & $\mathrm{M}$ & $\mathrm{M}$ & $\mathrm{S}$ & $\mathrm{M}$ & $\mathrm{M}$ & $S$ & $\mathrm{M}$ & $\mathrm{M}$ & PL & $\mathrm{PM}$ & $\mathrm{PM}$ & NM & NL \\
\hline & & & $\mathrm{Z}$ & $S$ & $\mathrm{M}$ & $\mathrm{L}$ & $\mathrm{M}$ & S & $\mathrm{M}$ & $\mathrm{L}$ & $\mathrm{L}$ & $\mathrm{L}$ & $\mathrm{M}$ & $\mathrm{S}$ & $\mathrm{M}$ & $\mathrm{L}$ & $\mathrm{M}$ & $S$ & $\mathrm{PM}$ & $\mathrm{PM}$ & $\mathrm{PM}$ & NM & $\mathrm{NM}$ \\
\hline & & & $\mathrm{PM}$ & $S$ & $S$ & $\mathrm{M}$ & $S$ & $S$ & $S$ & $\mathrm{M}$ & M & $\mathrm{M}$ & $S$ & $\mathrm{M}$ & $\mathrm{M}$ & S & $\mathrm{M}$ & $\mathrm{M}$ & PL & $\mathrm{PM}$ & $\mathrm{PM}$ & $\mathrm{NM}$ & NL \\
\hline & & & $\mathrm{PL}$ & $\mathrm{M}$ & $\mathrm{L}$ & $\mathrm{L}$ & $\mathrm{L}$ & $\mathrm{M}$ & $\mathrm{Z}$ & $\mathrm{Z}$ & $\mathrm{Z}$ & $\mathrm{Z}$ & $\mathrm{Z}$ & $\mathrm{S}$ & S & $\mathrm{Z}$ & S & S & PL & PL & $\mathrm{PM}$ & NL & NL \\
\hline & \multirow{5}{*}{$\mathrm{NM}$} & & NL & $\mathrm{M}$ & $\mathrm{L}$ & $\mathrm{L}$ & $\mathrm{L}$ & $\mathrm{M}$ & Z & $\mathrm{Z}$ & Z & Z & Z & $S$ & $S$ & Z & $S$ & $S$ & PL & $\mathrm{PM}$ & $\mathrm{PM}$ & NM & NL \\
\hline & & \multirow{4}{*}{$e$} & NM & $\mathrm{S}$ & S & $\mathrm{M}$ & S & $\mathrm{S}$ & $S$ & $\mathrm{M}$ & $\mathrm{M}$ & $\mathrm{M}$ & S & $\mathrm{M}$ & $\mathrm{M}$ & S & $\mathrm{M}$ & M & $\mathrm{PM}$ & $\mathrm{PM}$ & $\mathrm{Z}$ & NM & NM \\
\hline & & & $\mathrm{Z}$ & $S$ & $\mathrm{M}$ & $\mathrm{L}$ & $\mathrm{M}$ & $S$ & $\mathrm{M}$ & $\mathrm{L}$ & $\mathrm{L}$ & $\mathrm{L}$ & $\mathrm{M}$ & $S$ & $\mathrm{M}$ & $\mathrm{L}$ & $\mathrm{M}$ & $S$ & $\mathrm{PM}$ & $\mathrm{PM}$ & $\mathrm{Z}$ & NM & $\mathrm{NM}$ \\
\hline & & & $\mathrm{PM}$ & $S$ & $\mathrm{~S}$ & $\mathrm{M}$ & $\mathrm{S}$ & S & $S$ & $\mathrm{M}$ & $\mathrm{M}$ & $\mathrm{M}$ & S & $\mathrm{M}$ & $\mathrm{M}$ & S & $\mathrm{M}$ & $\mathrm{M}$ & $\mathrm{PM}$ & $\mathrm{PM}$ & $\mathrm{Z}$ & NM & NM \\
\hline & & & PL & $\mathrm{M}$ & $\mathrm{L}$ & $\mathrm{L}$ & $\mathrm{L}$ & $\mathrm{M}$ & Z & $\mathrm{Z}$ & Z & Z & Z & $\mathrm{S}$ & $S$ & Z & $S$ & $S$ & PL & $\mathrm{PM}$ & $\mathrm{PM}$ & $\mathrm{NM}$ & NL \\
\hline & \multirow{5}{*}{$\mathrm{Z}$} & \multirow{5}{*}{$e$} & NL & $\mathrm{M}$ & $\mathrm{L}$ & $\mathrm{L}$ & $\mathrm{L}$ & $\mathrm{M}$ & Z & $\mathrm{Z}$ & $\mathrm{Z}$ & $\mathrm{Z}$ & $\mathrm{Z}$ & $S$ & $S$ & $\mathrm{Z}$ & $S$ & $\mathrm{~S}$ & $\mathrm{Z}$ & $\mathrm{Z}$ & $\mathrm{Z}$ & $\mathrm{Z}$ & $\mathrm{Z}$ \\
\hline & & & $\mathrm{NM}$ & $S$ & $S$ & $\mathrm{M}$ & $S$ & $S$ & $S$ & $\mathrm{M}$ & $\mathrm{M}$ & $\mathrm{M}$ & $S$ & $\mathrm{M}$ & $\mathrm{M}$ & $S$ & $\mathrm{M}$ & $\mathrm{M}$ & Z & Z & $\mathrm{Z}$ & $\mathrm{Z}$ & $\mathrm{Z}$ \\
\hline & & & $\mathrm{Z}$ & $S$ & $\mathrm{M}$ & $\mathrm{L}$ & $\mathrm{M}$ & $S$ & $\mathrm{M}$ & $\mathrm{L}$ & $\mathrm{L}$ & $\mathrm{L}$ & $\mathrm{M}$ & $S$ & $\mathrm{M}$ & $\mathrm{L}$ & $\mathrm{M}$ & $S$ & $\mathrm{Z}$ & $\mathrm{Z}$ & $\mathrm{Z}$ & $\mathrm{Z}$ & $\mathrm{Z}$ \\
\hline & & & $\mathrm{PM}$ & $S$ & S & $\mathrm{M}$ & $S$ & $S$ & $S$ & $\mathrm{M}$ & $\mathrm{M}$ & $\mathrm{M}$ & $S$ & $\mathrm{M}$ & $\mathrm{M}$ & $S$ & $\mathrm{M}$ & $\mathrm{M}$ & Z & Z & Z & Z & Z \\
\hline & & & PL & $\mathrm{M}$ & $\mathrm{L}$ & $\mathrm{L}$ & $\mathrm{L}$ & $\mathrm{M}$ & Z & $\mathrm{Z}$ & Z & $\mathrm{Z}$ & Z & $S$ & $S$ & Z & $S$ & $S$ & Z & $\mathrm{Z}$ & $\mathrm{Z}$ & $\mathrm{Z}$ & Z \\
\hline & \multirow{5}{*}{$\mathrm{PM}$} & \multirow{5}{*}{$e$} & NL & $\mathrm{M}$ & $\mathrm{L}$ & $\mathrm{L}$ & $\mathrm{L}$ & $\mathrm{M}$ & Z & $\mathrm{Z}$ & $\mathrm{Z}$ & $\mathrm{Z}$ & Z & $\mathrm{S}$ & $\mathrm{S}$ & $\mathrm{Z}$ & $S$ & $\mathrm{~S}$ & NL & $\mathrm{PM}$ & $\mathrm{PM}$ & $\mathrm{NM}$ & PL \\
\hline & & & $\mathrm{NM}$ & $S$ & $S$ & $\mathrm{M}$ & $\mathrm{S}$ & $S$ & $S$ & $\mathrm{M}$ & $\mathrm{M}$ & $\mathrm{M}$ & $S$ & $\mathrm{M}$ & $\mathrm{M}$ & S & $\mathrm{M}$ & $\mathrm{M}$ & NM & $\mathrm{PM}$ & $\mathrm{Z}$ & $\mathrm{NM}$ & $\mathrm{PM}$ \\
\hline & & & $\mathrm{Z}$ & S & $\mathrm{M}$ & $\mathrm{L}$ & $\mathrm{M}$ & S & $\mathrm{M}$ & $\mathrm{L}$ & $\mathrm{L}$ & $\mathrm{L}$ & $\mathrm{M}$ & $\mathrm{S}$ & $\mathrm{M}$ & $\mathrm{L}$ & $\mathrm{M}$ & S & NM & $\mathrm{PM}$ & $\mathrm{Z}$ & NM & $\mathrm{PM}$ \\
\hline & & & $\mathrm{PM}$ & S & $\mathrm{S}$ & $\mathrm{M}$ & $\mathrm{S}$ & $S$ & $S$ & $\mathrm{M}$ & $\mathrm{M}$ & $\mathrm{M}$ & $\mathrm{S}$ & $\mathrm{M}$ & $\mathrm{M}$ & S & $\mathrm{M}$ & $\mathrm{M}$ & NM & $\mathrm{PM}$ & $\mathrm{Z}$ & $\mathrm{NM}$ & $\mathrm{PM}$ \\
\hline & & & $\mathrm{PL}$ & $\mathrm{M}$ & $\mathrm{L}$ & $\mathrm{L}$ & $\mathrm{L}$ & $\mathrm{M}$ & $\mathrm{Z}$ & $\mathrm{Z}$ & $\mathrm{Z}$ & $\mathrm{Z}$ & $\mathrm{Z}$ & $\mathrm{S}$ & $\mathrm{S}$ & $\mathrm{Z}$ & $\mathrm{S}$ & $\mathrm{S}$ & NL & $\mathrm{PM}$ & $\mathrm{PM}$ & NM & $\mathrm{PL}$ \\
\hline & \multirow{5}{*}{ PL } & \multirow{5}{*}{$e$} & NL & $\mathrm{M}$ & $\mathrm{L}$ & $\mathrm{L}$ & $\mathrm{L}$ & $\mathrm{M}$ & Z & $\mathrm{Z}$ & Z & $\mathrm{Z}$ & Z & $S$ & $S$ & $\mathrm{Z}$ & $S$ & $S$ & NL & PL & $\mathrm{PM}$ & NL & PL \\
\hline & & & NM & $\mathrm{S}$ & $S$ & $\mathrm{M}$ & $S$ & $\mathrm{~S}$ & S & $\mathrm{M}$ & $\mathrm{M}$ & $\mathrm{M}$ & S & $\mathrm{M}$ & $\mathrm{M}$ & $S$ & $\mathrm{M}$ & $\mathrm{M}$ & NL & $\mathrm{PM}$ & $\mathrm{PM}$ & $\mathrm{NM}$ & PL \\
\hline & & & $\mathrm{Z}$ & $S$ & $\mathrm{M}$ & $\mathrm{L}$ & $\mathrm{M}$ & S & $\mathrm{M}$ & $\mathrm{L}$ & $\mathrm{L}$ & $\mathrm{L}$ & $\mathrm{M}$ & $\mathrm{S}$ & $\mathrm{M}$ & $\mathrm{L}$ & $\mathrm{M}$ & $\mathrm{S}$ & NM & $\mathrm{PM}$ & $\mathrm{PM}$ & $\mathrm{NM}$ & $\mathrm{PM}$ \\
\hline & & & $\mathrm{PM}$ & S & $\mathrm{S}$ & $\mathrm{M}$ & $\mathrm{S}$ & $\mathrm{S}$ & S & $\mathrm{M}$ & $\mathrm{M}$ & $\mathrm{M}$ & $\mathrm{S}$ & $\mathrm{M}$ & $\mathrm{M}$ & S & $\mathrm{M}$ & $\mathrm{M}$ & NL & $\mathrm{PM}$ & $\mathrm{PM}$ & NM & $\mathrm{PL}$ \\
\hline & & & PL & $\mathrm{M}$ & $\mathrm{L}$ & $\mathrm{L}$ & $\mathrm{L}$ & $\mathrm{M}$ & Z & $\mathrm{Z}$ & $\mathrm{Z}$ & $\mathrm{Z}$ & $\mathrm{Z}$ & $S$ & $S$ & $\mathrm{Z}$ & $S$ & $S$ & NL & PL & $\mathrm{PM}$ & NL & PL \\
\hline
\end{tabular}
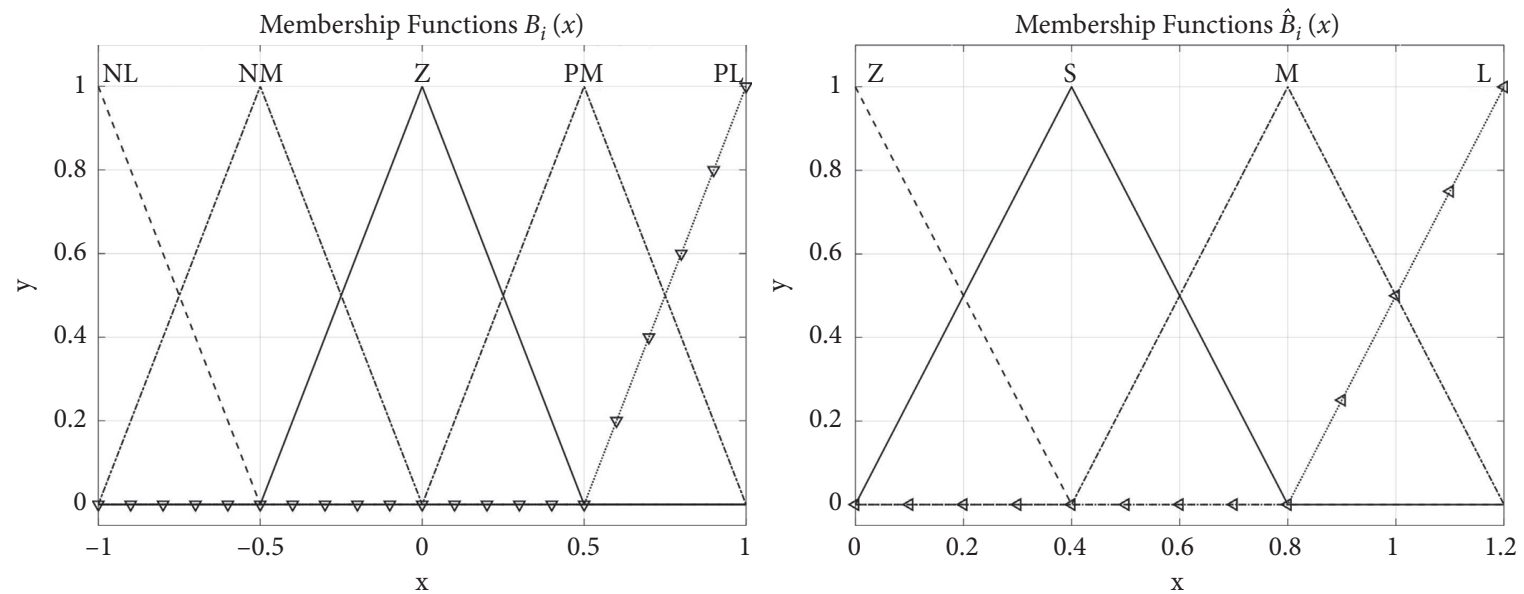

Figure 6: Membership function $B_{i}(x)$ corresponding to the fuzzy set $\{$ NL NM $Z$ PM PL $\}$ and membership function $\widehat{B}_{i}(x)$ corresponding to the fuzzy set. $\{\mathrm{Z} \mathrm{S} \mathrm{M} \mathrm{L}\}$.

3.2. Design of AUV Vertical and Horizontal Motion Controller. For the vertical motion of the AUV, in order to realize the simultaneous control of AUV position and attitude, a two-stage controller is adopted. The diagram of the two-stage ELM fuzzy PID controller for the vertical motion of the AUV is shown in Figure 7. The error of the depth $d_{c}-d$ is used as the input of the first-stage controller. The output of the first-stage controller is used as the expected pitch angle $\theta_{c}$ which is the input of the second-stage controller. The output value of the second stage controller is taken as the horizontal rudder angle $\delta_{e}$ of the AUV.

For the horizontal motion of the AUV, the two-stage ELM fuzzy PID controller is also adopted, as shown in Figure 8. The error of the cross-track distance $\mathrm{CTD}_{c}-\mathrm{CTD}$ is used as the input of the first-stage controller. The output of 


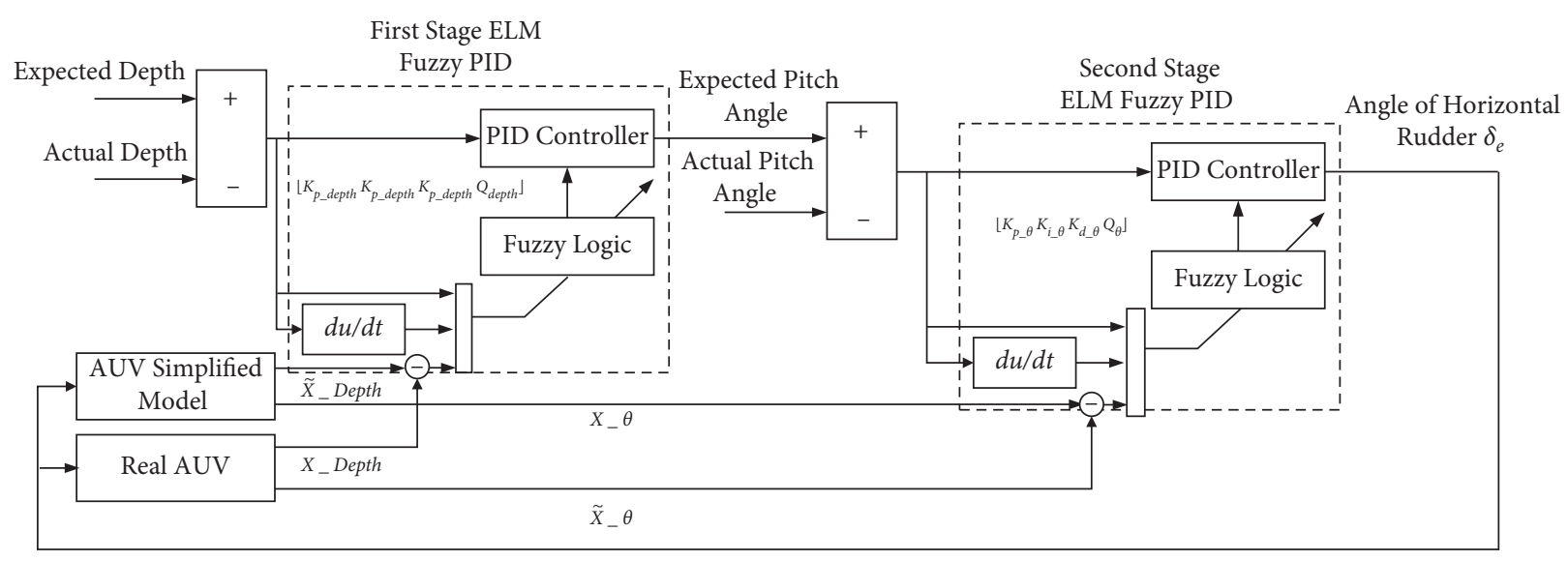

FIgURe 7: Diagram of the two-stage ELM fuzzy PID controller for the vertical motion of the AUV.

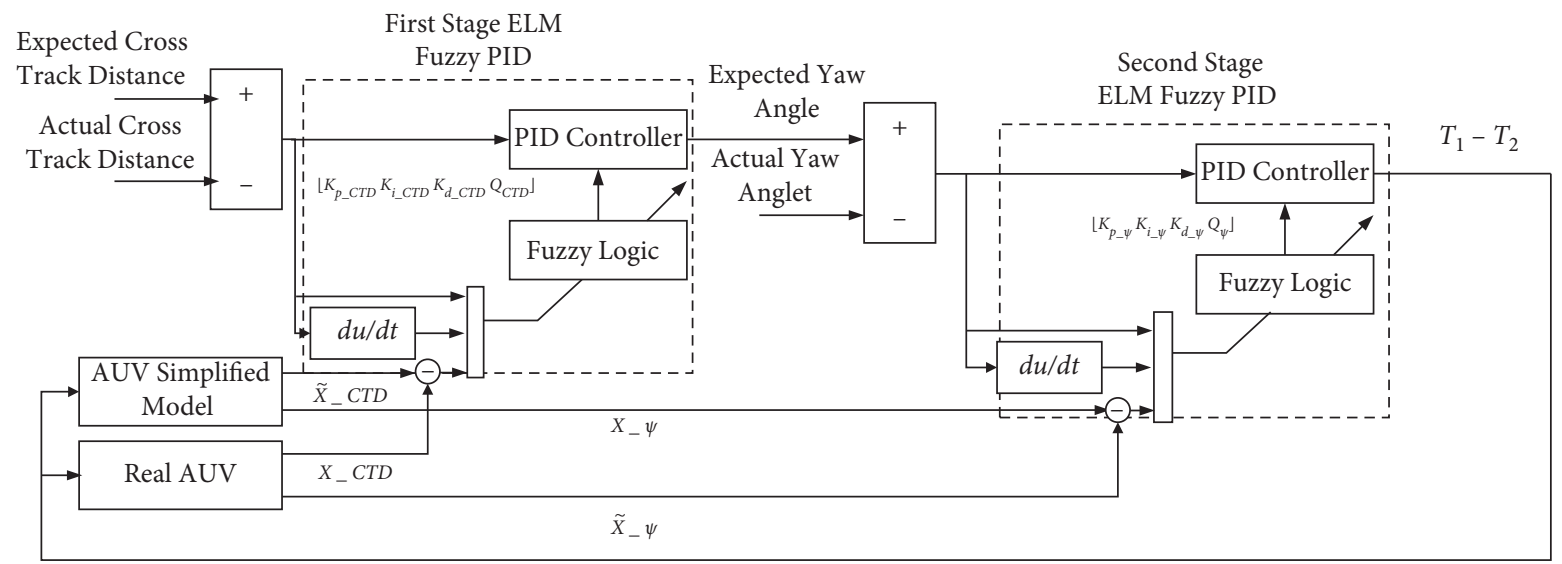

FIGURE 8: Diagram of the two-stage ELM fuzzy PID controller for the horizontal motion of the AUV.

the first-stage controller is used as the expected yaw angle $\psi_{c}$, which is the input of the second-stage controller. Thus, the output value of the second-stage controller is used as the difference of the two thrusters $T_{1}-T_{2}$ of the AUV.

\section{Simulation of ELM Fuzzy PID Control for AUV}

4.1. Wave Disturbance Model for AUV. In order to verify whether the control system can effectively suppress the disturbance of waves to the AUV, this study proposes a wave disturbance model to simulate the influence of waves to the AUV.

It is assumed that the wave disturbances to AUV are regular waves. The fluid studied satisfies the ideal fluid hypothesis of uniform, incompressible, nonviscous, and nonrotational. According to the Froude-Krylov hypothesis [36], the pressure distributions in regular waves are as follows: $p=\frac{\rho g H}{2} \cdot \frac{\cos h[k \cdot(z+h)]}{\cos h(k \cdot h)} \cdot \cos (k x \cos \theta-k y \sin \theta-\omega t)$,

where $\rho$ is the density of water, $g$ is the acceleration of gravity, $k$ is the wave number, $\omega$ is the wave frequency, $\gamma$ is the angle between the direction of AUV motion and the direction of wave travel, $h$ is the water depth, and $H$ is the wave height. For the six-degree-of-freedom movement of the AUV, the wave interference force is expressed as follows:

$$
\left\{\mathbf{F}=-\iint \mathbf{p} \cdot \mathbf{n d} S, \mathbf{M}=-\iint \mathbf{p} \cdot(\mathbf{n} \times \mathbf{r}) \mathrm{d} S,\right.
$$

where $S$ is the surface area of AUV, and $\mathbf{n}$ is the normal vector outside of AUV surface. By using Gauss theorem, the integral along the surface of the AUV can be transformed into volume integral, as shown in 


$$
\left\{\begin{array}{l}
F_{x}=-\iiint \frac{\partial p}{\partial x} \mathrm{~d} V \\
F_{y}=-\iiint \frac{\partial p}{\partial y} \mathrm{~d} V \\
F_{z}=-\iiint \frac{\partial p}{\partial z} \mathrm{~d} V \\
M_{x}=-\iiint\left(\frac{\partial p}{\partial z} y-\frac{\partial p}{\partial y} z\right) \mathrm{d} V \\
M_{y}=-\iiint\left(\frac{\partial p}{\partial x} z-\frac{\partial p}{\partial z} x\right) \mathrm{d} V \\
M_{z}=-\iiint\left(\frac{\partial p}{\partial y} x-\frac{\partial p}{\partial x} y\right) \mathrm{d} V
\end{array}\right.
$$

where $V$ is the volume of the AUV. As shown in Figure 9, the AUV can be approximately simplified to a cylinder of equal diameter. By substituting equations (20)-(22), and considering the ocean depth as infinite, the interference force and moment of the waves on the AUV can be simplified as follows:

$$
\begin{aligned}
& F_{x}=E_{x} \cdot \frac{2 \rho g \pi H}{k^{2} \sin \gamma} \cdot \frac{\cos h[k \cdot(-D+h)+k R / 2] \cdot \sin h(k R / 2)}{\cos h(k h)} \cdot \cos \left(\omega t-\frac{k L \cos \gamma-k R \sin \gamma}{2}\right) \sin \left(\frac{k R \sin \gamma}{2}\right) \cos \left(\frac{k L \cos \gamma}{2}\right), \\
& F_{y}=E_{y} \cdot \frac{2 \rho g \pi H}{k^{2} \cos \gamma} \cdot \frac{\cos h[k \cdot(-D+h)+k R / 2] \cdot \sin h(k R / 2)}{\cos h(k h)} \cdot \cos \left(\omega t-\frac{k L \cos \gamma-k R \sin \gamma}{2}\right) \sin \left(-\frac{k R \sin \gamma}{2}\right) \sin \left(\frac{k L \cos \gamma}{2}\right), \\
& F_{z}=E_{z} \cdot \frac{2 \rho g \pi H}{k^{2} \cos \gamma \sin \gamma} \cdot \frac{\sin h[k \cdot(-D+h)+k R / 2] \cdot \sin h(k R / 2)}{\cos h(k h)} \cdot \cos \left(\omega t-\frac{k L \cos \gamma-k R \sin \gamma}{2}\right) \sin \left(\frac{k R \sin \gamma}{2}\right) \sin \left(\frac{k l \cos \gamma}{2}\right), \\
& M_{x}=\frac{\rho g \pi H D_{x}\left(e^{k D+k R}-e^{k D}\right)}{k^{3} \cos \gamma} \cdot\left[\begin{array}{c}
\left(k D-1-\frac{1}{\sin ^{2} \gamma}\right) \cdot 2 \sin \left(\omega t-\frac{k L \cos \gamma-k R \sin \gamma}{2}\right) \sin \left(\frac{k R \sin \gamma}{2}\right) \cos \left(\frac{k L \cos \gamma}{2}\right) \\
+k R \sin \gamma \sin \left(\frac{k L \cos \gamma}{2}\right) \sin \left(\omega t+k R \sin \gamma-\frac{k L \cos \gamma}{2}\right)
\end{array}\right], \\
& M_{y}=\frac{\rho g \pi H D_{y}\left(e^{k D+k R}-e^{k D}\right)}{k^{3} \sin \gamma} \cdot\left[\begin{array}{c}
\left(-k D+1+\frac{1}{\cos ^{2} \gamma}\right) \cdot 2 \sin \left(\omega t-\frac{k L \cos \gamma-k R \sin \gamma}{2}\right) \sin \left(\frac{k R \sin \gamma}{2}\right) \sin \left(\frac{k L \cos \gamma}{2}\right) \\
+\frac{L}{k \cos \gamma} \sin \left(\frac{k R \sin \gamma}{2}\right) \sin \left(\omega t+k L \cos \gamma-\frac{k R \sin \gamma}{2}\right)
\end{array}\right], \\
& M_{z}=\frac{\rho g \pi H D_{z}\left(e^{k D+k R}-e^{k D}\right)}{k^{2} \sin ^{2} \gamma} \cdot\left[\begin{array}{c}
R \sin \gamma \cos \left(\omega t+k R \sin \gamma-\frac{k L \cos \gamma}{2}\right) \sin \left(\frac{k L \cos \gamma}{2}\right) \\
+L \cos \gamma \sin \left(\frac{k R \sin \gamma}{2}\right) \cos \left(\omega t-k L \cos \gamma+\frac{k R \sin \gamma}{2}\right)
\end{array}\right]
\end{aligned}
$$




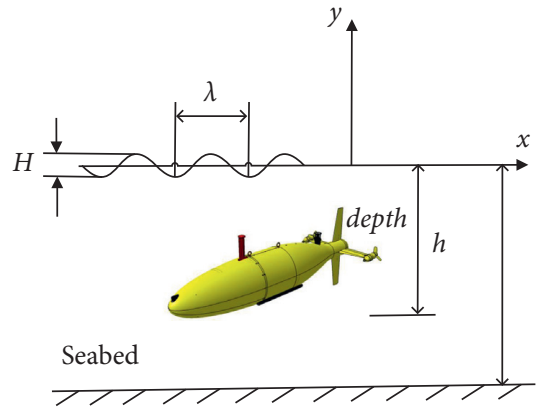

FIgURE 9: Diagram of AUV under wave disturbance.

wherein $E_{x}, E_{y}, E_{z}, D_{x}, D_{y}$, and $D_{z}$ are diffraction coefficients of waves in the directions of six-degrees-of-freedom of the AUV, respectively.

The wave scales are shown in Table 3 . According to the international wave scales, waves are divided into ten levels. During the actual process, AUVs are generally affected by waves below the SLIGHT, which are usually the CALMRIPPLED and the SMOOTH-WAVELET. Generally, the AUV missions are not performed in the SLIGHT level and above.

According to the wave disturbance model established above, the wave force and moment on the AUV decrease with the depth. AUV is most vulnerable to instability in shallow water due to interference. Therefore, the simulation is performed when the initial depth of AUV is 5 meters.

4.2. Design of Simulation Test. The model of the AUV and its ELM fuzzy PID controller is established in Matlab Simulink as shown in Figure 10. The dynamic equation of the AUV is realized by using the 6DOF module in Simulink, and four modules are established to simulate the real force and moment acting on the AUV, which are hydrodynamic force module, gravity module, control force module, and wave disturbance force module, respectively. The controller includes two channels, which are vertical motion control channel and horizontal motion control channel. The structure of the two control channels is shown in Chapter 3.2 , and the embedded linear model of the AUV is established by S-function.

In order to verify the control effect of the ELM fuzzy PID controller when AUV is sailing in a straight line, simulation test I is designed as follows: the AUV maintains a fixed depth of 5 meters and sails to the north direction at a speed of 4 knots. During the simulation, the wave disturbance model established above is adopted to disturb the AUV. Under the disturbance of CALM-RIPPLED, SMOOTH-WAVELET, and SLIGHT waves, as a comparison, the classical PID, normal fuzzy PID, and ELM fuzzy PID are simulated, respectively. The structure of the classical PID controller is similar to the controller proposed by Hammad et al. [37] The structure of the fuzzy PID controller is similar to the controller proposed by Zhang et al. [38] The basic information setting in the simulation process is shown in Table 4.

It is necessary to verify the control ability of the ELM fuzzy PID controller in the process of AUV depth changing or horizontal transformation. Thus, simulation test II is designed as follows: the AUV sails to the north direction at a speed of 4 knots under the disturbance of the CALMRIPPLED, SMOOTH-WAVELET, and SLIGHT waves, respectively. At the time of $20 \mathrm{~s}$, the depth transfers from $5 \mathrm{~m}$ to $10 \mathrm{~m}$. Similar to test I, the classical PID, normal fuzzy PID, and ELM fuzzy PID are simulated for comparison. The simulation information is shown in Table 4.

Simulation test III is similar to test II. The AUV sails to the north direction at a speed of 4 knots, and the cross-track distance of the AUV transfers from $0 \mathrm{~m}$ to $5 \mathrm{~m}$ at $20 \mathrm{~s}$. During the simulation, the AUV is disturbed by the three kinds of waves. The classical PID, normal fuzzy PID, and ELM fuzzy PID are simulated for comparison. The simulation information is shown in Table 4.

Since the actuator has a time delay when executing the control signal, it is considered to set the reaction time of the actuator to 0.2 seconds in the simulation process. Considering the influence of rudder surface saturation, the saturation values of the elevator and yaw rudder are set to 10 degrees.

\section{Results and Analysis}

5.1. Results of Test I. For test I, Figure 11 shows the vertical control simulation results of classical PID, normal fuzzy PID, and ELM fuzzy PID in test I when AUV is straightly sailing in the three waves. The comparison of the vertical motion control results of the three methods is shown in Table 5. Figure 12 shows the horizontal control simulation results of the three control methods in test I. As it can be indicated from the figures, the comparison of the horizontal motion control results of the three methods is shown in Table 6.

Figure 13 shows the control signal of the elevator in the pitch direction. It can be seen from the figure that the control signal of the ELM fuzzy PID control method is stronger than the other two control methods. The rudder saturation occurs several times at the beginning of the simulation. But the control strength decreases after the first wave disturbance cycle, and the rudder saturation does not appear. But the control strength is still the largest of the three methods. The ELM fuzzy PID control method has a stronger ability to sense disturbance, because the slope of its control signal is the largest and response speed is the fastest.

Based on these, the following conclusions can be drawn: first, the classical PID controller can ensure the stability of AUV that keeps a direct route in CALM-RIPPLED waves. However, in SMOOTH-WAVELET waves, the motion stability of AUV is seriously affected. Furthermore, in the SLIGHT waves, the oscillation of the AUV with the classical PID controller makes it to basically lose the working ability. The AUV with a normal fuzzy PID controller has the ability to keep straightly sailing under the disturbance of CALMRIPPLED and SMOOTH-WAVELET waves. But its stability begins to be affected under the disturbance of SLIGHT waves. However, the ELM fuzzy PID controller is able to keep the AUV stable under the disturbance of all the three waves. 
TABLE 3: International wave scale. Source: https://wenku.baidu.com/view/98aac42e25284b73f242336c1eb91a37f1113286.html.

\begin{tabular}{|c|c|c|}
\hline $\begin{array}{l}\text { Wave scale } \\
\text { name }\end{array}$ & $\begin{array}{l}\text { Wave height } \\
\text { range }\end{array}$ & Description of sea surface \\
\hline Calm-glassy & $0 \mathrm{~m}$ & The sea surface is as smooth as a mirror, or there are only swells \\
\hline Calm-rippled & $0-0.1 \mathrm{~m}$ & Ripple and swell exist at the same time \\
\hline Smooth-wavelet & $0.1-0.5 \mathrm{~m}$ & The waves are very small, the crest begins to break, and the spray is not white but glassy \\
\hline Slight & $0.5-1.25 \mathrm{~m}$ & The crests of the waves are broken, and some of them form white spray \\
\hline Moderate & $1.25-2.50 \mathrm{~m}$ & Waves have distinct shapes and form white waves everywhere \\
\hline Rough & $2.50-4.0 \mathrm{~m}$ & $\begin{array}{c}\text { There were big wave crests, the spray occupied a large area on the crest, and the wind began to cut off } \\
\text { the spray on the crest }\end{array}$ \\
\hline Very rough & 4 & The wave crests sometimes appear the long wave shape of storm wave \\
\hline High & & The crests of the waves were covered with spray \\
\hline Very high & $9-14 \mathrm{~m}$ & $\begin{array}{c}\text { Dense spray covered the slope of the waves, and the sea turned white except in certain places within } \\
\text { the trough }\end{array}$ \\
\hline Phenomenal & $>14 \mathrm{~m}$ & $\begin{array}{c}\text { The whole sea surface is covered with dense spray layer, the air is full of water droplets, and the } \\
\text { visibility is significantly reduced }\end{array}$ \\
\hline
\end{tabular}

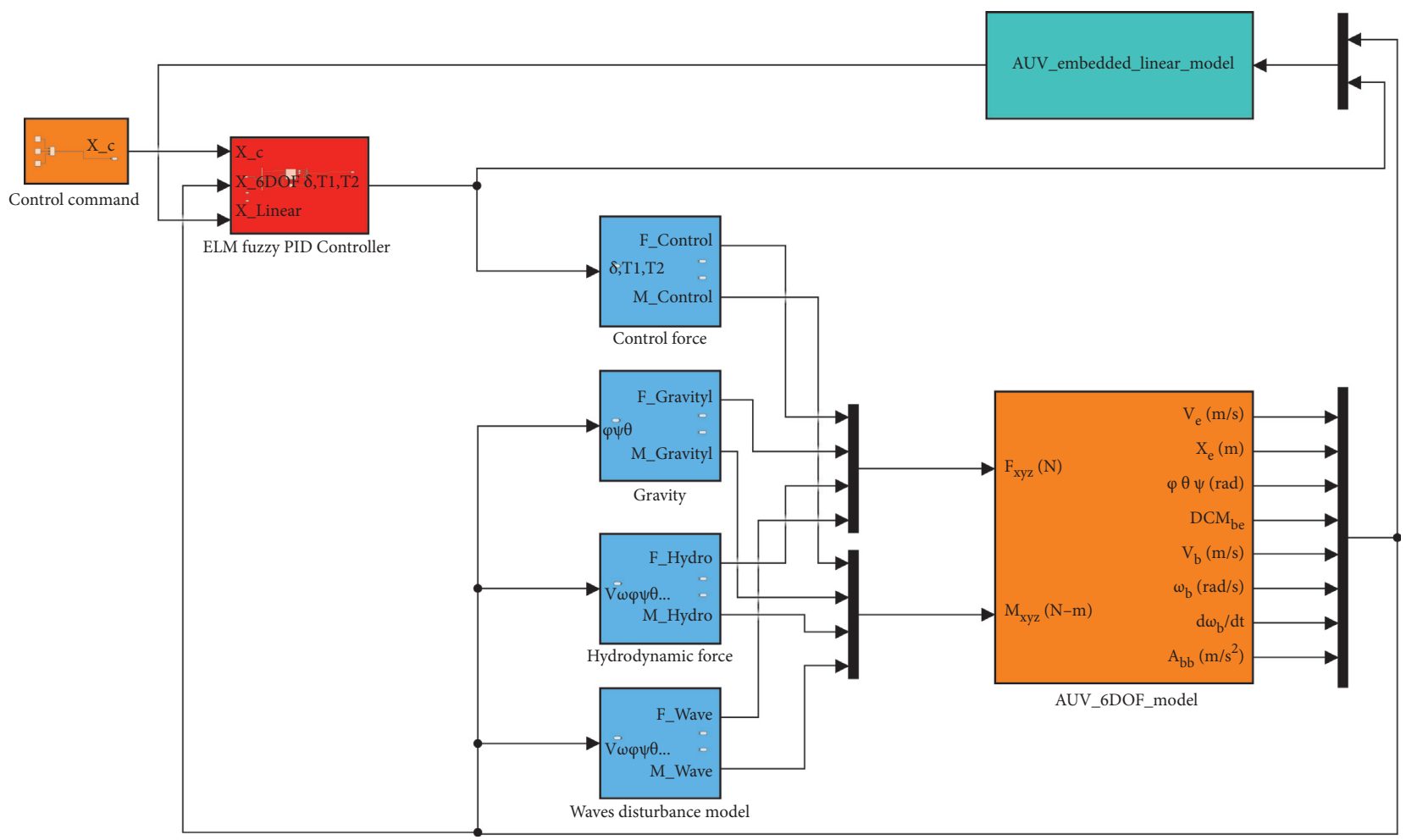

FIGURE 10: AUV model and its controller in Simulink under wave disturbance.

Figure 14 shows the control signal of the yaw rudder in the yaw direction. It can be seen from the figure that, similar to the pitch direction, the control signal of the ELM fuzzy PID control method is stronger than the other two control methods. The control force is the largest in each wave disturbance cycle, and there is no rudder saturation in the simulation process. Moreover, the ELM fuzzy PID control method has a stronger ability to sense a disturbance in the yaw direction and it has a faster response speed.

5.2. Results of Test II. For test II, Figure 15 shows the trajectory and attitude angles of the AUV with the three control methods under the disturbance of CALM-RIPPLED, SMOOTH-WAVELET, and SLIGHT waves. The trajectories of PID and trajectory of normal fuzzy PID are translated in the negative direction of $Z$ axis in order to explicitly express the three trajectories. Table 7 shows the critical parameters of the control process of depth transformation. As it can be summarized from the figures, the AUV with the classical PID controller is able to maintain stability in the process of depth transformation under the disturbance of CALMRIPPLED waves. But in SMOOTH-WAVELET and SLIGHT waves, the depth transformation process is unable to maintain stability, while the overshoot is over $40 \%$. Furthermore, the variation of attitude angles and position is also 
TABLE 4: Controller tuning parameters and basic information used in the simulation.

\begin{tabular}{|c|c|c|c|}
\hline Simulation information & Classical PID & Normal fuzzy PID & ELM fuzzy PID \\
\hline Duration of simulation/s & $40 \mathrm{~s}$ (test I)/50 s (test II, III) & $40 \mathrm{~s}$ (test I) $/ 50 \mathrm{~s}$ (test II, III) & $40 \mathrm{~s}$ (test I) $/ 50 \mathrm{~s}$ (test II, III) \\
\hline Step size/s & $0.01 \mathrm{~s}$ & $0.01 \mathrm{~s}$ & $0.01 \mathrm{~s}$ \\
\hline Iterative method & Runge-Kutta & Runge-Kutta & Runge-Kutta \\
\hline$K_{p-\text { depth }}$ & 0.02 & {$[0,0.05]$} & {$[0,0.05]$} \\
\hline$K_{i_{-} \text {depth }}^{p-\text { deptn }}$ & 0.005 & {$[0,0.01]$} & {$[0,0.01]$} \\
\hline$K_{d_{-} \text {depth }}$ & 0.02 & {$[0,0.05]$} & {$[0,0.05]$} \\
\hline$Q_{\text {depth }}$ & - & - & {$[-0.1,0.1]$} \\
\hline$K_{p_{-} \theta}$ & 1 & {$[0,2]$} & {$[0,2]$} \\
\hline$K_{i_{-} \theta}^{p_{-0}}$ & 0 & {$[0,0.01]$} & {$[0,0.01]$} \\
\hline$K_{d_{-} \theta}$ & 1 & {$[0,2]$} & {$[0,2]$} \\
\hline$Q_{\theta}$ & - & - & {$[-0.01,0.01]$} \\
\hline$K_{p_{-} \mathrm{CTD}}$ & 0.005 & {$[0,0.01]$} & {$[0,0.01]$} \\
\hline$K_{i_{-} \text {CTD }}^{p_{-}}$ & 0 & {$[0,0.01]$} & {$[0,0.01]$} \\
\hline$K_{d_{-} \mathrm{CTD}}$ & 0.0005 & {$[0,0.001]$} & {$[0,0.001]$} \\
\hline$Q_{\text {CTD }}^{u_{-C I D}}$ & - & - & {$[-0.1,0.1]$} \\
\hline$K_{p_{-} \psi}$ & 1 & {$[0,2]$} & {$[0,2]$} \\
\hline$K_{i_{-} \psi}^{p_{-}}$ & 0 & {$[0,0.01]$} & {$[0,0.01]$} \\
\hline$K_{d_{-} \psi}^{l_{-} \psi}$ & 3 & {$[0,5]$} & {$[0,0.01]$} \\
\hline$Q_{\psi}^{u_{-\psi}}$ & - & - & {$[-0.01,0.01]$} \\
\hline
\end{tabular}

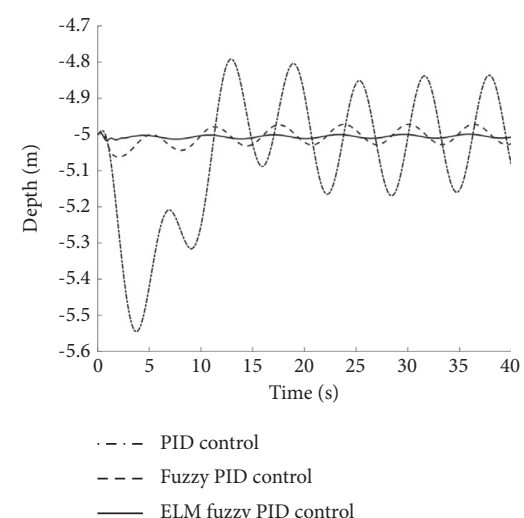

(a)

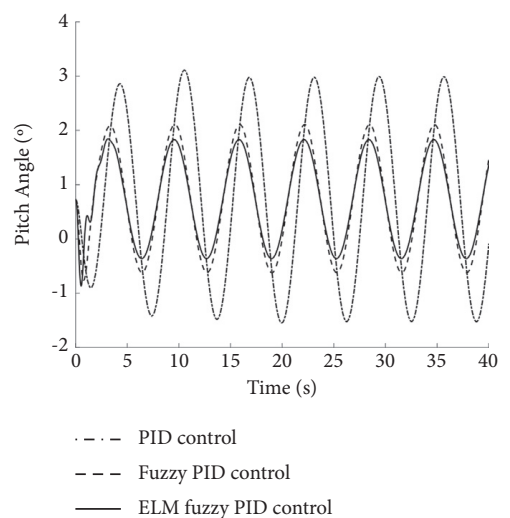

(d)
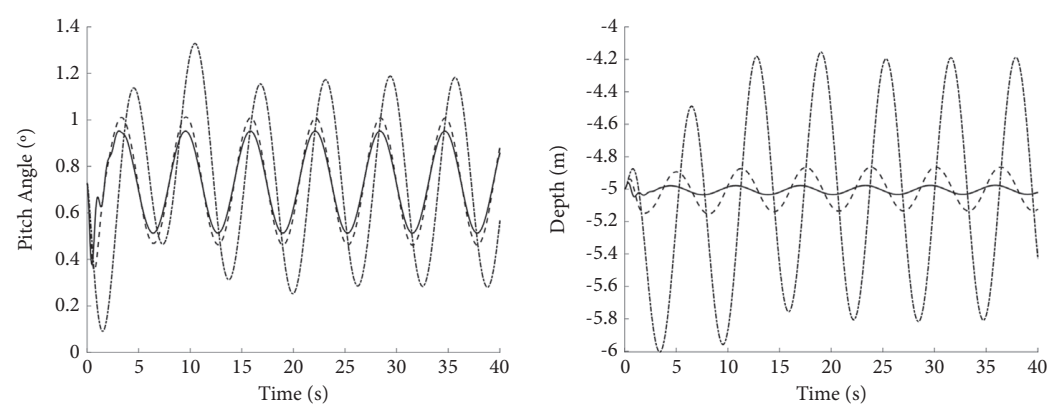

$\begin{array}{ll}- & \text { PID control } \\ -- & \text { Fuzzy PID control } \\ & \text { _ ELM fuzzy PID control }\end{array}$

(b)

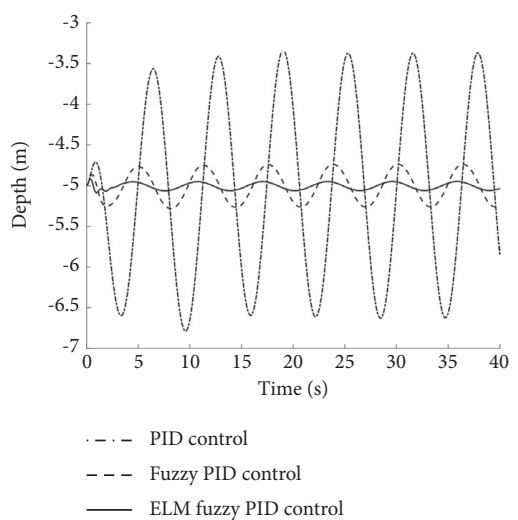

(e)

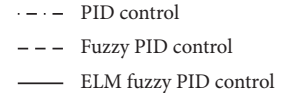

(c)

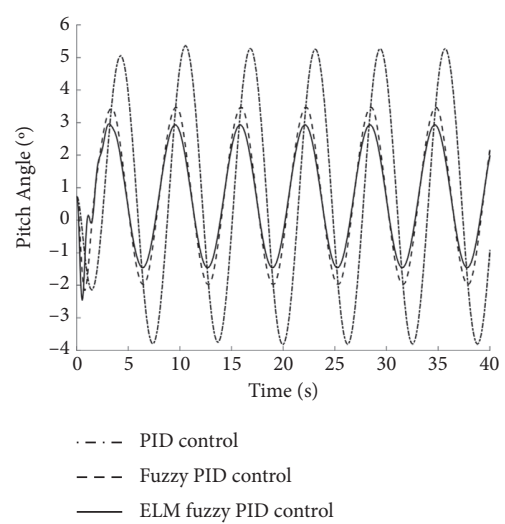

(f)

FIGURE 11: Variation of AUV depth $d$ under the disturbance of the CALM-RIPPLED waves (a), SMOOTH-WAVELET waves (c), and SLIGHT waves (e), and variation of AUV pitch angle $\theta$ under the disturbance of the CALM-RIPPLED waves (b), SMOOTH-WAVELET waves (d), and SLIGHT waves (f). 
TABLE 5: Comparison of the vertical motion control results of classical PID, normal fuzzy PID, and ELM PID controller under the disturbance of three waves in test I.

\begin{tabular}{|c|c|c|c|}
\hline Simulation results & Classical PID & Fuzzy PID & ELM fuzzy PID \\
\hline Amplitude of depth (calm-rippled) & $0.3 \mathrm{~m}$ & $0.1 \mathrm{~m}$ & $0.01 \mathrm{~m}$ \\
\hline Average error of depth (calm-rippled) & $0.132 \mathrm{~m}$ & $0.0265 \mathrm{~m}$ & $0.0077 \mathrm{~m}$ \\
\hline Amplitude of pitch angle (calm-rippled) & $1^{\circ}$ & $0.5^{\circ}$ & $0.4^{\circ}$ \\
\hline Average error of pitch angle (calm-rippled) & $0.2896^{\circ}$ & $0.1862^{\circ}$ & $0.1457^{\circ}$ \\
\hline Amplitude of depth (smooth-wavelet) & $1.6 \mathrm{~m}$ & $0.3 \mathrm{~m}$ & $0.05 \mathrm{~m}$ \\
\hline Average error of depth (smooth-wavelet) & $0.512 \mathrm{~m}$ & $0.0737 \mathrm{~m}$ & $0.0188 \mathrm{~m}$ \\
\hline Amplitude of pitch angle (smooth-wavelet) & $4.5^{\circ}$ & $2.5^{\circ}$ & $2^{\circ}$ \\
\hline Average error of pitch angle (smooth-wavelet) & $1.4081^{\circ}$ & $0.8748^{\circ}$ & $0.7191^{\circ}$ \\
\hline Amplitude of depth (slight) & $3 \mathrm{~m}$ & $0.6 \mathrm{~m}$ & $0.1 \mathrm{~m}$ \\
\hline Average error of depth (slight) & $1.0154 \mathrm{~m}$ & $0.1418 \mathrm{~m}$ & $0.0367 \mathrm{~m}$ \\
\hline Amplitude of pitch angle (slight) & $9^{\circ}$ & $5.2^{\circ}$ & $4.2^{\circ}$ \\
\hline Average error of pitch angle (slight) & $2.8223^{\circ}$ & $1.7282^{\circ}$ & $1.4378^{\circ}$ \\
\hline
\end{tabular}

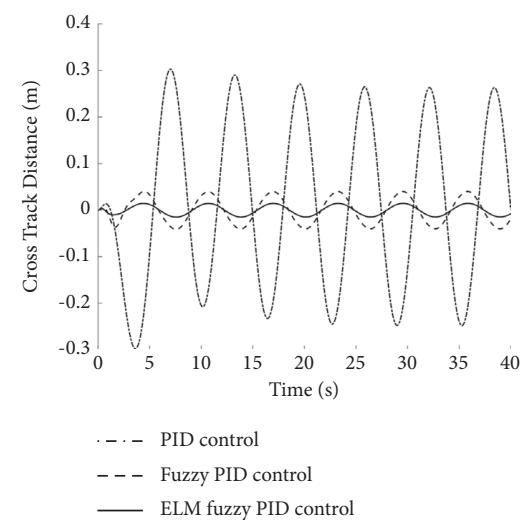

(a)

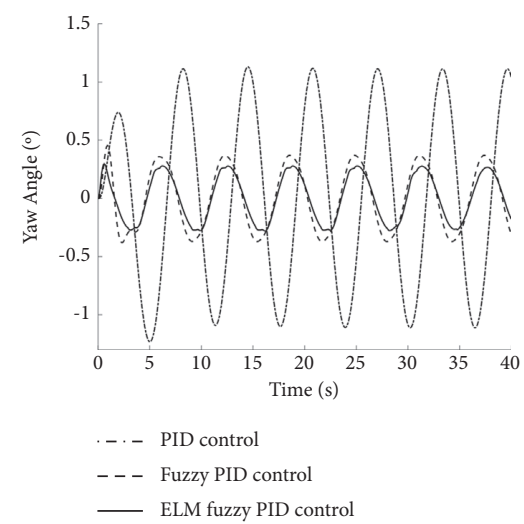

(d)

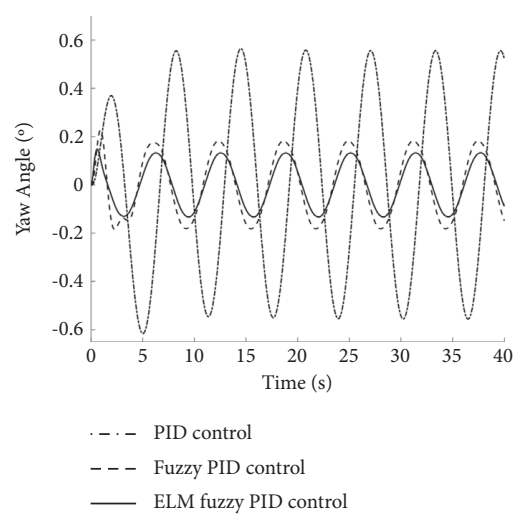

(b)

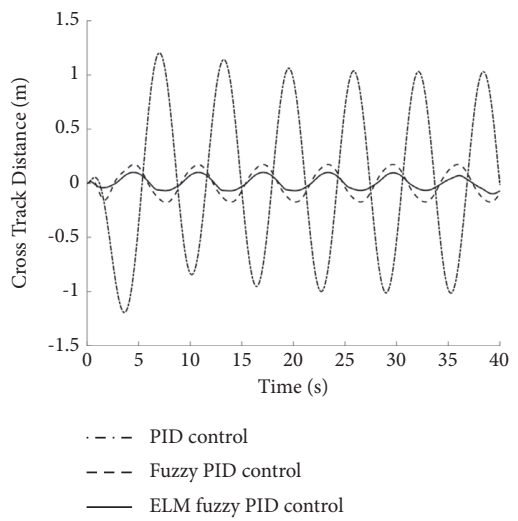

(e)

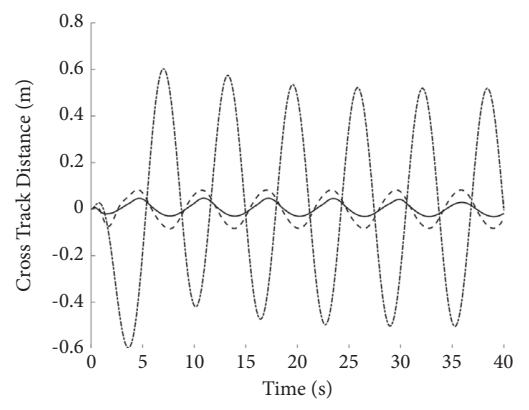

-..- PID control

- - - Fuzzy PID control

_ ELM fuzzy PID control

(c)

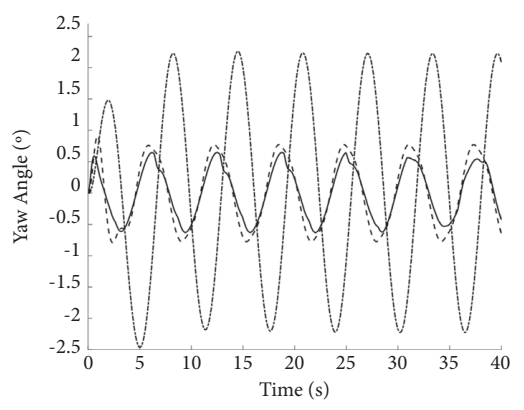

-.. PID control

- - - Fuzzy PID control

—_ ELM fuzzy PID control

(f)

FIGURE 12: Variation of AUV cross-track distance $z$ under the disturbance of the CALM-RIPPLED waves (a), SMOOTH-WAVELET waves (c), and SLIGHT waves (e), and variation of AUV yaw angle $\psi$ under the disturbance of the CALM-RIPPLED waves (b), SMOOTHWAVELET waves (d), and SLIGHT waves (f).

unacceptable. For the normal fuzzy PID controller, it makes the overshoot less and variation smaller. It can maintain the stability of AUV in the process of depth transformation under the disturbance of CALM-RIPPLED, SMOOTHWAVELET, and SLIGHT waves. For the ELM fuzzy PID controller, it is able to maintain the stability of AUV in the process under the three different wave scales. Its variation of attitude angles and position is the smallest of the three methods. In addition, the response speed is the fastest and the overshoot is small enough to keep stable under the three wave scales.

5.3. Results of Test III. For test III, Figure 16 shows the trajectory and attitude angles of the AUV with the three control methods in test III under the disturbance of the three 
TABLE 6: Comparison of the horizontal motion control results of classical PID, normal fuzzy PID, and ELM PID controller under the disturbance of three waves in test I.

\begin{tabular}{|c|c|c|c|}
\hline Simulation results & Classical PID & Fuzzy PID & ELM fuzzy PID \\
\hline Amplitude of cross-track distance (calm-rippled) & $0.5 \mathrm{~m}$ & $0.1 \mathrm{~m}$ & $0.04 \mathrm{~m}$ \\
\hline Average error of cross-track distance (calm-rippled) & $0.1610 \mathrm{~m}$ & $0.0173 \mathrm{~m}$ & $0.0061 \mathrm{~m}$ \\
\hline Amplitude of yaw angle (calm-rippled) & $1.1^{\circ}$ & $0.38^{\circ}$ & $0.25^{\circ}$ \\
\hline Average error of yaw angle (calm-rippled) & $0.3453^{\circ}$ & $0.1339^{\circ}$ & $0.0877^{\circ}$ \\
\hline Amplitude of cross-track distance (smooth-wavelet) & $1 \mathrm{~m}$ & $0.2 \mathrm{~m}$ & $0.1 \mathrm{~m}$ \\
\hline Average error of cross-track distance (smooth-wavelet) & $0.3215 \mathrm{~m}$ & $0.0355 \mathrm{~m}$ & $0.0129 \mathrm{~m}$ \\
\hline Amplitude of yaw angle (smooth-wavelet) & $2.3^{\circ}$ & $0.7^{\circ}$ & $0.5^{\circ}$ \\
\hline Average error of yaw angle (smooth-wavelet) & $0.6906^{\circ}$ & $0.2701^{\circ}$ & $0.1810^{\circ}$ \\
\hline Amplitude of cross-track distance (slight) & $2 \mathrm{~m}$ & $0.4 \mathrm{~m}$ & $0.2 \mathrm{~m}$ \\
\hline Average error of cross-track distance (slight) & $0.6426 \mathrm{~m}$ & $0.0736 \mathrm{~m}$ & $0.0301 \mathrm{~m}$ \\
\hline Amplitude of yaw angle (slight) & $4.5^{\circ}$ & $1.5^{\circ}$ & $1.2^{\circ}$ \\
\hline Average error of yaw angle (slight) & $1.3817^{\circ}$ & $0.5476^{\circ}$ & $0.3750^{\circ}$ \\
\hline
\end{tabular}

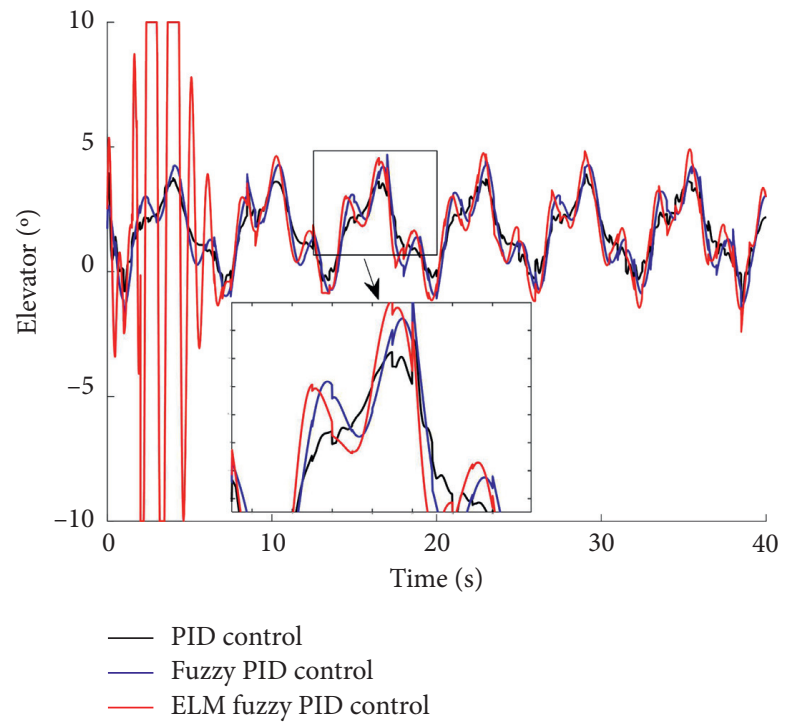

Figure 13: The control signal of the elevator in the pitch direction.

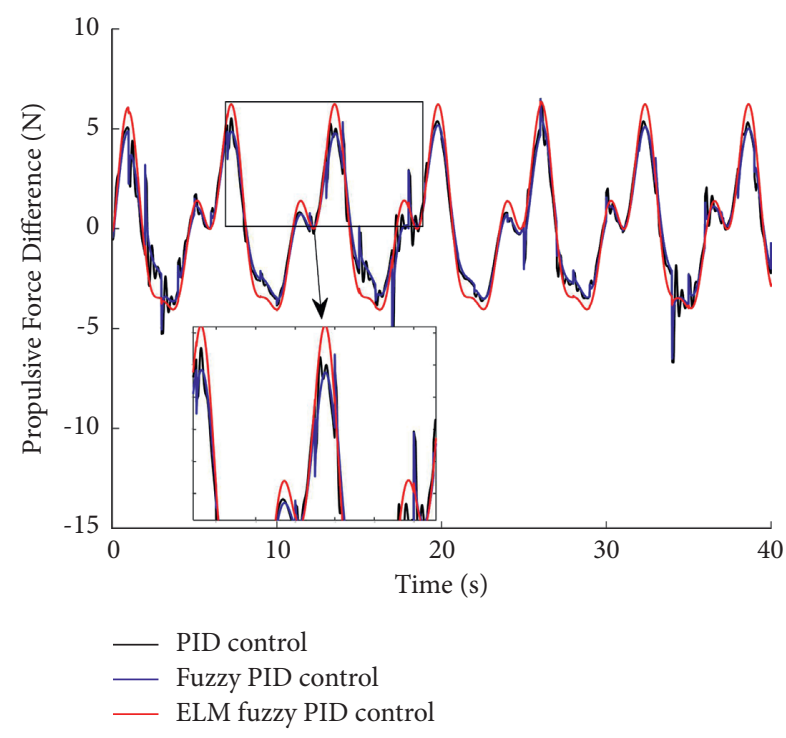

Figure 14: The control signal of left and right propulsive force difference in the yaw direction. waves. Similar to test II, the trajectory of PID and trajectory of normal fuzzy PID are translated in the negative direction of $Z$ axis in order to explicitly express the three trajectories. Table 8 shows the critical parameters of the control process of horizontal transformation. The results are consistent with test II. For the PID controller, the AUV with the classical PID controller is able to maintain stability in the process of horizontal transformation under the disturbance of CALMRIPPLED waves. But in SMOOTH-WAVELET and SLIGHT waves, the variation of the attitude angles and position is violent and unacceptable. Furthermore, the response speed is the slowest of the three methods. For the normal fuzzy PID controller, there is an improvement in the response speed and variation range. The overshoot of the cross-track distance is less than 20\%; consequently, it can maintain the stability of AUV in the process of horizontal transformation under the disturbance of CALM-RIPPLED, SMOOTHWAVELET, and SLIGHT waves. However, the horizontal variation is tended to be a little bit large in the SLIGHT waves. For the ELM fuzzy PID controller, it is able to maintain the stability of the AUV in the process under all the 


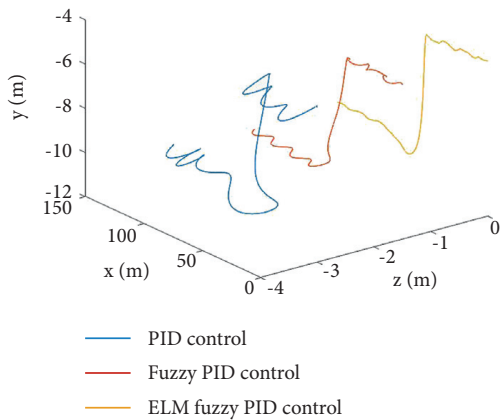

(a)

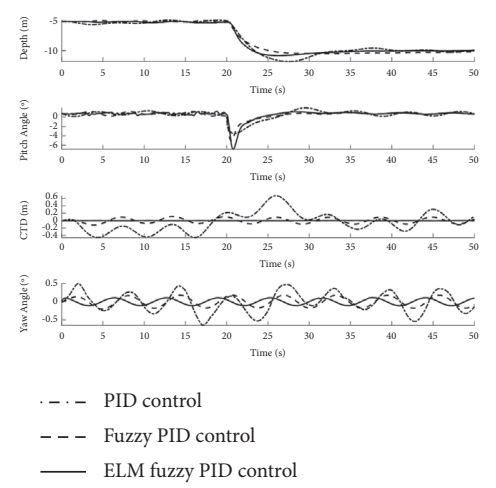

(d)

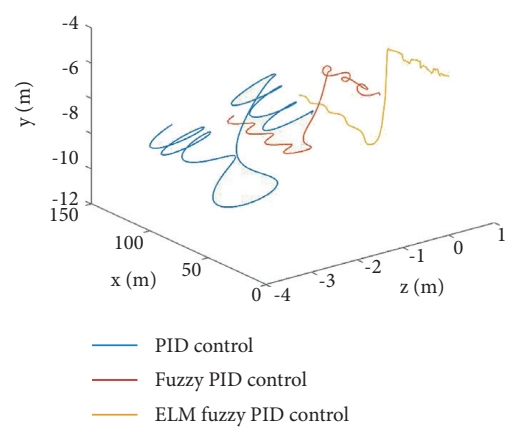

(b)

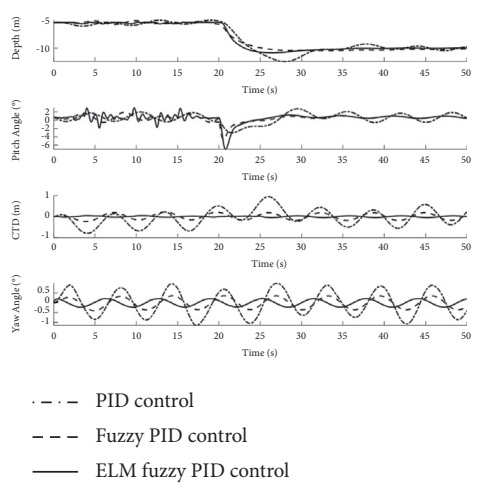

(e)

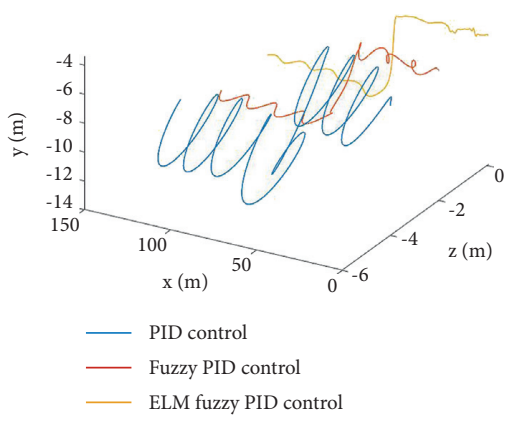

(c)

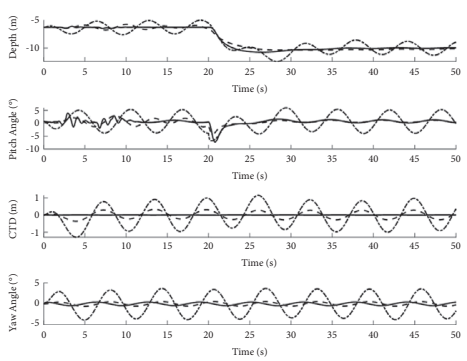

-. - PID control

- - - Fuzzy PID control

— ELM fuzzy PID control

(f)

FIGURE 15: Trajectory of AUV with the three control methods when the depth $d$ changes from $5 \mathrm{~m}$ to $10 \mathrm{~m}$ under the disturbance of CALMRIPPLED waves (a), SMOOTH-WAVELET waves (b), and SLIGHT waves (c), and variation of attitudes and position of the AUV under the disturbance of CALM-RIPPLED waves (d), SMOOTH-WAVELET waves (e), and SLIGHT waves (f).

TABLE 7: Comparison of the control results of classical PID, normal fuzzy PID, and ELM PID controller under the disturbance of three waves in test II.

\begin{tabular}{lccc}
\hline Simulation results & Classical PID & Normal fuzzy PID & ELM fuzzy PID \\
\hline Response time of depth in test II (calm-rippled) & $3.45 \mathrm{~s}$ & $4.73 \mathrm{~s}$ & $2.87 \mathrm{~s}$ \\
Overshoot of depth in test II (calm-rippled) & $1.82 \mathrm{~m}$ & $0.47 \mathrm{~m}$ & $0.77 \mathrm{~m}$ \\
Response time of depth in test II (smooth-wavelet) & $3.92 \mathrm{~s}$ & $5.29 \mathrm{~s}$ & $3.08 \mathrm{~s}$ \\
Overshoot of depth in test II (smooth-wavelet) & $2.57 \mathrm{~m}$ & $0.48 \mathrm{~m}$ & $0.88 \mathrm{~m}$ \\
Response time of depth in test II (slight) & $2.34 \mathrm{~s}$ & $5.36 \mathrm{~s}$ & $3.01 \mathrm{~s}$ \\
Overshoot of depth in test II (slight) & $3.18 \mathrm{~m}$ & $0.47 \mathrm{~m}$ & $0.97 \mathrm{~m}$ \\
\hline
\end{tabular}

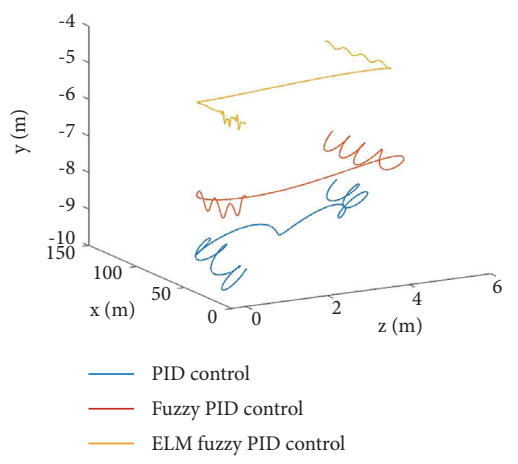

(a)

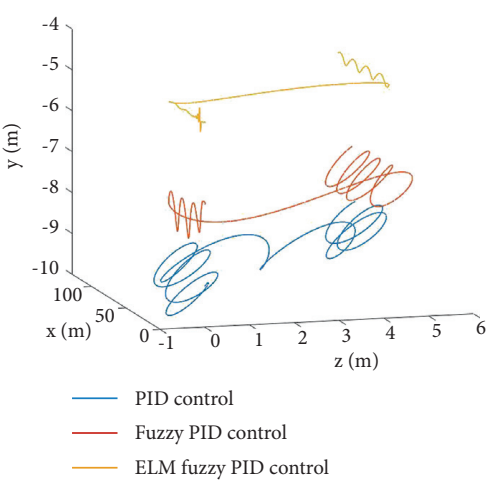

(b)

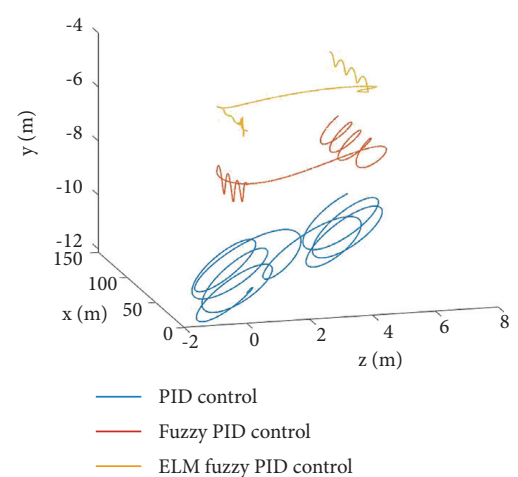

(c)

Figure 16: Continued. 


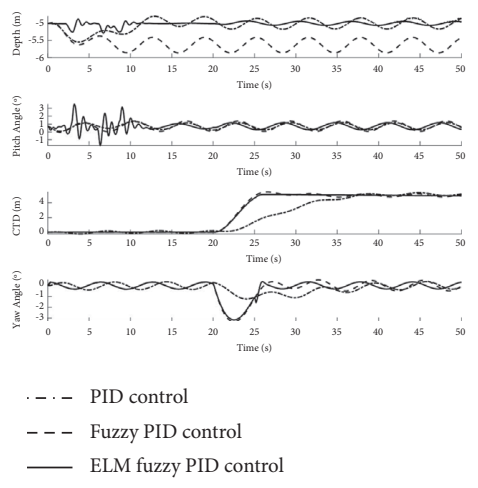

(d)

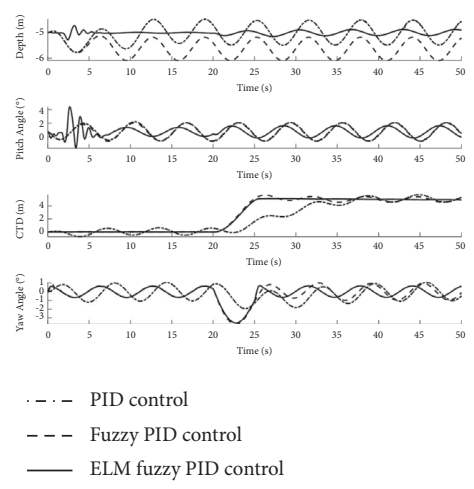

(e)

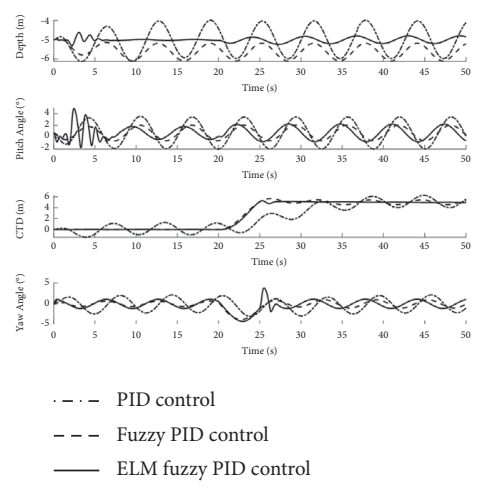

(f)

FIgURE 16: Trajectory of AUV with the three control methods when the cross-track distance CTD changes from $0 \mathrm{~m}$ to $5 \mathrm{~m}$ (left) under the disturbance of CALM-RIPPLED waves (a), SMOOTH-WAVELET waves (b), and SLIGHT waves (c), and variation of attitudes and position of the AUV under the disturbance of CALM-RIPPLED waves (d), SMOOTH-WAVELET waves (e), and SLIGHT waves (f).

TABLE 8: Comparison of the control results of classical PID, normal fuzzy PID, and ELM PID controller under the disturbance of three waves in test III.

\begin{tabular}{lccc}
\hline Simulation results & Classical PID & Normal fuzzy PID & ELM fuzzy PID \\
\hline Response time of CTD in test III (calm-rippled) & $6.95 \mathrm{~s}$ & $5.12 \mathrm{~s}$ & $5.56 \mathrm{~s}$ \\
Overshoot of CTD in test III (calm-rippled) & $0.20 \mathrm{~m}$ & $0.46 \mathrm{~m}$ & $0.13 \mathrm{~m}$ \\
Response time of CTD in test III (smooth-wavelet) & $7.23 \mathrm{~s}$ & $4.87 \mathrm{~s}$ & $5.26 \mathrm{~s}$ \\
Overshoot of CTD in test III (smooth-wavelet) & $0.58 \mathrm{~m}$ & $0.65 \mathrm{~m}$ & $0.12 \mathrm{~m}$ \\
Response time of CTD in test III (slight) & $11.82 \mathrm{~s}$ & $4.91 \mathrm{~s}$ & $4.92 \mathrm{~s}$ \\
Overshoot of CTD in test III (slight) & $1.12 \mathrm{~m}$ & $0.67 \mathrm{~m}$ & $0.31 \mathrm{~m}$ \\
\hline
\end{tabular}

three different wave scales. Its variation of attitudes and position is the smallest of the three methods. The overshoot is less than the normal fuzzy PID controller. In addition, the response speed is almost as fast as the fuzzy PID controller.

\section{Conclusions}

In this study, a new ELM fuzzy PID controller is introduced to the AUV under the disturbance of ocean waves. An ocean wave disturbance model is established in order to simulate the force acting on the AUV. Finally, the control effect of the ELM fuzzy PID control system under the disturbance of CALM-RIPPLED, SMOOTH-WAVELET, and SLIGHT waves is simulated by using the established wave disturbance model to AUV.

From the results of simulations, the conclusion can be drawn as below: compared with the classical PID controller and the normal fuzzy PID controller, the ELM fuzzy PID controller can achieve a better control effect when the AUV disturbed by waves, which mainly reflected in three aspects: stability, response speed, and overshoot. In the first aspect, the ELM fuzzy PID controller can significantly reduce the wave disturbance to AUV and enhance the stability, especially in large wave disturbance. In the second aspect, the simulation results show that the AUV with the ELM fuzzy PID controller achieves a comprehensive optimization of response speed in all the three wave scales. In the last aspect, the overshoot of the AUV with the ELM fuzzy PID controller is small enough to keep the stability after the transformation in all the three wave scales.

The research results can be applied to various types of AUV, which can reduce their own posture oscillations when AUV takes photographs or detects sonar signals, thereby reducing the overlap of detection images or reducing the difficulty of camera focusing. Moreover, it can obviously improve the maneuverability and robustness of the AUV and then improve the ability to perform missions in large wave conditions.

\section{Data Availability}

The data used to support the findings of this study are available from the corresponding author upon request.

\section{Conflicts of Interest}

The authors declare that they have no conflicts of interest

\section{Authors' Contributions}

Da Lyu contributed to conceptualization, methodology, software, simulation, and writing. Haoqin Su contributed to supervision and project administration. Mingyu Guo contributed to data curation and review. Zijun Zhang contributed to data curation and writing. Hao Long contributed to project administration and simulation. Junbo Zhao contributed to supervision and project administration. 


\section{Acknowledgments}

The authors would like to thank the support from the Science and Technology Committee of China Aerospace Science and Technology Corporation (grant number: 8000090003014160021) and the Premium Funding Project for Academic Human Resources Development in the Beijing Union University (BPHR2020CZ03). This work was supported by the Hydrodynamics Technology Research Group in China Academy of Aerospace Aerodynamics.

\section{References}

[1] L. Yongkuan, "AUV's trends over the world in the future decade," in Proceedings of the 1992 Symposium on Autonomous Underwater Vehicle Technology, pp. 116-127, Washington, DC, USA, June 1992.

[2] J. Zhang, G. Han, J. Sha, Y. Qian, and J. Liu, "AUV-assisted subsea exploration method in $6 \mathrm{G}$ enabled deep ocean based on a cooperative pac-men mechanism," IEEE Transactions on Intelligent Transportation Systems, vol. 23, no. 2, 2021.

[3] R. B. Wynn, V. A. I. Huvenne, T. P. Le Bas et al., "Autonomous Underwater Vehicles (AUVs): their past, present and future contributions to the advancement of marine geoscience," Marine Geology, vol. 352, pp. 451-468, 2014.

[4] S. Bloomer, M. Kowalczyk, P. Kowalczyk, S. Constable, E. Haber, and T. Kasuga, "AUV-CSEM: an improvement in the efficiency of multi-sensor mapping of seafloor massive sulfide (SMS) deposits with an AUV," in Proceedings of the 2018 OCEANS - MTS/IEEE Kobe Techno-Oceans (OTO), pp. 1-7, Kobe, Japan, May 2018.

[5] R. Wynn, B. Bett, A. Evans et al., "Investigating the Feasibility of Utilizing AUV and Glider Technology for Mapping and Monitoring of the UK MPA Network," Final report for Defra project MB0118, National Oceanography Centre, Southampton, UK, 2013.

[6] S. Bauk, N. Kapidani, Ž. Lukšic, F. Rodrigues, and L. Sousa, "Autonomous marine Vehicles in Sea Surveillance as One of the COMPASS2020 Project Concerns," in Proceedings of the International Maritime and Port Technology and Development Conference and International Conference on Maritime Autonomous Surface Ships, vol. 1357, November 2019, Article ID 12045.

[7] F. S. Tabataba-Nasab, A. K. Khalaji, and S. A. A. Moosavian, "Adaptive nonlinear control of an autonomous underwater vehicle," Transactions of the Institute of Measurement and Control, vol. 41, no. 11, pp. 3121-3131, 2019.

[8] V. N. Azarskov, V. I. Skurikhin, L. S. Zhiteckii, and R. O. Lypoi, "Modern control theory applied to inventory control for a manufacturing system," IFAC Proceedings Volumes, vol. 46, no. 9, pp. 1200-1205, 2013.

[9] J. Iqbal, "Modern control laws for an articulated robotic arm," Engineering, Technology \& Applied Science Research, vol. 9, no. 2, pp. 4057-4061, 2019.

[10] A. Zolghadri, "Modern control theory and real-world aerospace applications: I love you, nor do I," IFAC-PapersOnLine, vol. 50, no. 1, pp. 6446-6451, 2017.

[11] S. Wu, Cooperative Guidance and Control of Missiles Autonomous Formation, Springer, Berlin, Germany, 2019.

[12] J. Wan, B. He, D. Wang, T. Yan, and Y. Shen, "Fractionalorder PID motion control for AUV using cloud-model-based quantum genetic algorithm," IEEE Access, vol. 7, Article ID 124828, 2019.
[13] M. H. Khodayari and S. Balochian, "Design of adaptive fuzzy fractional order PID controller for autonomous underwater vehicle (AUV) in heading and depth attitudes," International Journal of Maritime Engineering, vol. 158, no. A1, 2016.

[14] J. Guerrero, J. Torres, V. Creuze, A. Chemori, and E. Campos, "Saturation based nonlinear PID control for underwater vehicles: design, stability analysis and experiments," Mechatronics, vol. 61, pp. 96-105, 2019.

[15] A. Leva, M. Bonvini, and M. Maggio, "Object-oriented modelling of industrial PID controllers," IFAC Proceedings Volumes, vol. 45, no. 3, pp. 152-157, 2012.

[16] J. Lesprier, J. M. Biannic, and C. Roos, "Modeling and robust nonlinear control of a fixed-wing UAV," in Proceedings of the 2015 IEEE Conference on Control Applications (CCA), pp. 1334-1339, Sydney, NSW, Australia, September 2015.

[17] J. Zhao, H. Zhang, and X. Li, "Active disturbance rejection switching control of quadrotor based on robust differentiator," Systems Science and Control Engineering, vol. 8, no. 1, pp. 605-617, 2020.

[18] S. Motta and F. Pappalardo, "Mathematical modeling of biological systems," Briefings in Bioinformatics, vol. 14, no. 4, pp. 411-422, 2012.

[19] S. Scher and G. Messori, "Predicting weather forecast uncertainty with machine learning," Quarterly Journal of the Royal Meteorological Society, vol. 144, no. 717, pp. 2830-2841, 2018.

[20] H. Li, Z. Zhang, H. Yan, and X. Xie, “Adaptive event-triggered fuzzy control for uncertain active suspension systems," IEEE Transactions on Cybernetics, vol. 49, no. 12, pp. 4388-4397, 2019.

[21] L. Zadeh, "Fuzzy sets," Information and Control, vol. 8, no. 3, pp. 338-353, 1965.

[22] C. C. Lee, "Fuzzy logic in control systems: fuzzy logic controller," I. IEEE Transactions on Systems, Man, and Cybernetics, vol. 20, no. 2, pp. 404-418, 1990.

[23] S. Smith, G. Rae, D. Anderson, and A. Shein, "Fuzzy logic control of an autonomous underwater vehicle," Control Engineering Practice, vol. 2, no. 2, pp. 321-331, 1994.

[24] D. A. Nguyen, D. Duy Thanh, N. T. Tien, and P. V. Anh, "Fuzzy controller design for autonomous underwater vehicles path tracking," in Proceedings of the 2019 International Conference on System Science and Engineering (ICSSE), pp. 592-598, Dong Hoi, Vietnam, July 2019.

[25] M. Rabah, A. Rohan, S. A. S. Mohamed, and S. H. Kim, "Autonomous moving target-tracking for a UAV quadcopter based on fuzzy-PI," IEEE Access, vol. 7, Article ID 38407, 2019.

[26] A. Nouri, I. Salhi, E. Elwarraki, S. El Beid, and N. Essounbouli, "DSP-based implementation of a self-tuning fuzzy controller for three-level boost converter," Electric Power Systems Research, vol. 146, pp. 286-297, 2017.

[27] S. Farajdadian and S. H. Hosseini, "Design of an optimal fuzzy controller to obtain maximum power in solar power generation system," Solar Energy, vol. 182, pp. 161-178, 2019.

[28] M. Septyan and T. Agustinah, "Trajectory tracking automated guided vehicle using fuzzy controller," in Proceedings of the 2019 International Conference of Artificial Intelligence and Information Technology (ICAIIT), pp. 169-174, Yogyakarta, Indonesia, March 2019.

[29] R. Raj and B. Mohan, "Stability analysis of general TakagiSugeno fuzzy two-term controllers," Fuzzy Information and Engineering, vol. 10, no. 2, pp. 196-212, 2018.

[30] X. Yan, M. Chen, G. Feng, Q. Wu, and S. Shao, "Fuzzy robust constrained control for nonlinear systems with input 
saturation and external disturbances," IEEE Transactions on Fuzzy Systems, vol. 29, no. 2, 2019.

[31] K. Sun, S. Mou, J. Qiu, T. Wang, and H. Gao, "Adaptive fuzzy control for nontriangular structural stochastic switched nonlinear systems with full state constraints," IEEE Transactions on Fuzzy Systems, vol. 27, no. 8, pp. 1587-1601, 2018.

[32] C. Yang, Y. Jiang, J. Na, Z. Li, L. Cheng, and C. Y. Su, "Finitetime convergence adaptive fuzzy control for dual-arm robot with unknown kinematics and dynamics," IEEE Transactions on Fuzzy Systems, vol. 27, no. 3, pp. 574-588, 2018.

[33] C. T. Chao, N. Sutarna, J. S. Chiou, and C. J. Wang, "An optimal fuzzy PID controller design based on conventional PID control and nonlinear factors," Applied Sciences, vol. 9, no. 6, p. 1224, 2019.

[34] G. A. Elnashar, "Dynamics modelling, performance evaluation and stability analysis of an autonomous underwater vehicle," International Journal of Modelling, Identification and Control, vol. 21, no. 3, pp. 306-320, 2014.

[35] W. Phillips and B. Santana, "Aircraft small-disturbance theory with longitudinal-lateral coupling," Journal of Aircraft, vol. 39, no. 6, pp. 973-980, 2002.

[36] T. Battista, C. Woolsey, T. Perez, and F. Valentinis, “A dynamic model for underwater vehicle maneuvering near a free surface," IFAC-PapersOnLine, vol. 49, no. 23, pp. 68-73, 2016.

[37] M. M. Hammad, A. K. Elshenawy, and M. El Singaby, "Position control and stabilization of fully actuated AUV using PID controller," in Proceedings of the SAI Intelligent Systems Conference, pp. 517-536, Springer, London, UK, September 2016.

[38] W. Zhang, H. Wang, X. Bian, Z. Yan, and G. Xia, “The application of self-tuning fuzzy PID control method to recovering AUV," in Proceedings of the 2012 Oceans, pp. 1-5, Hampton Roads, VA, USA, October 2012. 